\title{
Society for Immunotherapy of Cancer (SITC) clinical practice guideline on immune effector cell-related adverse events
}

\author{
Marcela V Maus (D) , ${ }^{1}$ Sara Alexander, ${ }^{2}$ Michael R Bishop (D) , ${ }^{3}$ \\ Jennifer N Brudno (i) , ${ }_{4}$ Colleen Callahan, ${ }^{5}$ Marco L Davila id , , Claudia Diamonte, ${ }^{7}$ \\ Jorg Dietrich, ${ }^{8}$ Julie C Fitzgerald, ${ }^{9}$ Matthew J Frigault (1) , ${ }^{10}$ Terry J Fry, ${ }^{11}$ \\ Jennifer L Holter-Chakrabarty (D) , ${ }^{12}$ Krishna V Komanduri, ${ }^{13}$ Daniel W Lee, ${ }^{14}$ \\ Frederick L Locke (D) , ${ }^{15}$ Shannon L Maude, ${ }^{5,16}$ Philip L McCarthy (D) , ${ }^{17}$ \\ Elena Mead, ${ }^{18}$ Sattva S Neelapu, ${ }^{19}$ Tomas G Neilan (D) , ${ }^{20}$ Bianca D Santomasso, ${ }^{21}$ \\ Elizabeth J Shpall, ${ }^{22}$ David T Teachey (D) , ${ }^{23}$ Cameron J Turtle (D) , ${ }^{24}$ \\ Tom Whitehead, ${ }^{25}$ Stephan A Grupp (D) ${ }^{26}$
}

To cite: Maus MV, Alexander S, Bishop MR, et al. Society for Immunotherapy of Cancer (SITC) clinical practice guideline on immune effector cell-related adverse events. Journal for ImmunoTherapy of Cancer 2020;8:e001511. doi:10.1136/ jitc-2020-001511

Accepted 12 0ctober 2020
Check for updates

(c) Author(s) (or their employer(s)) 2020. Re-use permitted under CC BY-NC. No commercial re-use. See rights and permissions. Published by BMJ.

For numbered affiliations see end of article.

Correspondence to Dr Stephan A Grupp; grupp@chop.edu

Dr Marcela V Maus; mvmaus@mgh.harvard.edu

\section{ABSTRACT}

Immune effector cell (IEC) therapies offer durable and sustained remissions in significant numbers of patients with hematological cancers. While these unique immunotherapies have improved outcomes for pediatric and adult patients in a number of disease states, as 'living drugs,' their toxicity profiles, including cytokine release syndrome (CRS) and immune effector cell-associated neurotoxicity syndrome (ICANS), differ markedly from conventional cancer therapeutics. At the time of article preparation, the US Food and Drug Administration (FDA) has approved tisagenlecleucel, axicabtagene ciloleucel, and brexucabtagene autoleucel, all of which are IEC therapies based on genetically modified $\mathrm{T}$ cells engineered to express chimeric antigen receptors (CARs), and additional products are expected to reach marketing authorization soon and to enter clinical development in due course. As IEC therapies, especially CAR T cell therapies, enter more widespread clinical use, there is a need for clear, cohesive recommendations on toxicity management, motivating the Society for Immunotherapy of Cancer (SITC) to convene an expert panel to develop a clinical practice guideline. The panel discussed the recognition and management of common toxicities in the context of IEC treatment, including baseline laboratory parameters for monitoring, timing to onset, and pharmacological interventions, ultimately forming evidence- and consensus-based recommendations to assist medical professionals in decision-making and to improve outcomes for patients.

\section{INTRODUCTION}

Immunotherapy is now established as a fourth pillar of cancer treatment, along with surgery, radiation, and chemotherapy. Genetically modified $\mathrm{T}$ cells are a novel form of immunotherapy, characterized by highly efficient and specific targeting of tumor cells when compared with checkpoint inhibitors. At the time of writing this article, three autologous $\mathrm{T}$ cell products engineered to express a chimeric antigen receptor (CAR), tisagenlecleucel, axicabtagene ciloleucel, and brexucabtagene autoleucel, ${ }^{1-3}$ have been approved by the US Food and Drug Administration (FDA) and multiple international health authorities, based on demonstrated durable and sustained remissions in a significant number of patients with relapsed and refractory hematological cancers that formerly had a dismal prognosis. ${ }^{4-11}$ All three products target CD19 and are indicated for the treatment of certain relapsed or refractory (RR) $\mathrm{B}$ cell derived hematological malignancies, specifically acute lymphoblastic leukemia (ALL) in children and young adults (tisagenlecleucel) and certain types of aggressive B cell lymphomas in adults (tisagenlecleucel, axicabtagene ciloleucel, and brexucabtagene autoleucel). Studies are ongoing for CD19-targeted CAR $\mathrm{T}$ therapies in additional hematological malignancies, including mantle cell lymphoma (MCL) and follicular lymphoma. ${ }^{2-14}$ CAR $\mathrm{T}$ cell therapies targeting antigens other than CD19 are also rapidly progressing through clinical trials. The most advanced at the time of publication are bb2121 (idecabtagene vicleucel) ${ }^{1516}$ and JNJ-4528, ${ }^{17}$ both of which target B cell maturation antigen (BCMA) and both of which were granted breakthrough therapy designation by the FDA. At the time of manuscript publication, more than 500 active clinical trials investigating CAR $\mathrm{T}$ cell therapies for 
cancer were registered with the United States National Library of Medicine.

As 'living drugs', however, the adverse events associated with CAR T cell therapy differ markedly from those seen with other anticancer regimens. Some of the most commonly reported toxicities include cytokine release syndrome (CRS), immune effector cell-associated neurotoxicity syndrome (ICANS), hemophagocytic lymphohistiocytosis (HLH), and persistent cytopenias and resultant infections, among others. ${ }^{18-22}$ During the pivotal phase II ELIANA trial of tisagenlecleucel in children and young adults with RR ALL, $73 \%$ of patients experienced grade 3 or 4 adverse events, and CRS occurred in $77 \%$ of patients. ${ }^{23}$ Similarly, in the ZUMA-1 trial, which was foundational for the approval of axicabtagene ciloleucel in adults with RR large cell lymphoma, $95 \%$ of patients experienced grade 3 or higher adverse events, with neurological events occurring in $64 \%$ of patients. ${ }^{24}$ Although the adverse events associated with CAR T cells and other immune effector cell (IEC) therapies are generally manageable with proper supportive care, the toxicities that do occur may have rapid onset and can progress to life-threatening events. Therefore, timely recognition and appropriate management of these toxicities are vital for safe use of IEC therapies.

To provide expert guidance to practicing clinicians using IEC therapies, the Society for Immunotherapy of Cancer (SITC) established an expert panel dedicated to IEC-related adverse events. The panel included expert perspectives from physicians, nursing, and patient advocacy, and considered issues related to patient monitoring, toxicity management, and interventions, with the goal of preparing recommendations on best practices for addressing toxicities during treatment with FDAapproved CAR $\mathrm{T}$ cell therapies, as well as other emerging IEC therapies. Note that familiarity and adherence to these guidelines do not replace formal accreditation by the Foundation for the Accreditation of Cellular Therapy (FACT) or similar regulatory bodies; formal IEC accreditation is strongly recommended by the authors to any clinical center that plans to offer these therapies to their patients.

\section{METHODS}

\section{Guideline development process}

The Institute of Medicine's (IOM) Standards for Developing Trustworthy Clinical Practice Guidelines were used as a model to develop the evidence- and consensus-based recommendations in this article. IOM standards dictate that guideline development is led by a multidisciplinary team using a transparent process where both funding sources and conflicts of interest are readily reported. Recommendations are based on literature evidence, where possible, and clinical experience, where appropriate. ${ }^{25}$ The American Society for Hematology (ASH), the American Society for Transplantation and Cellular Therapy (ASTCT), FACT at the University of Nebraska Medical Center, and the Emily Whitehead Foundation also provided representatives to serve on SITC's Immune Effector Cell-related Adverse Events Expert Panel. For transparency, a draft of this clinical practice guideline was made publicly available for comment after journal submission. All comments were considered for inclusion into the final article. This clinical practice guideline is intended to provide guidance and is not a substitute for the professional judgment of individual treating physicians.

\section{Evidence and consensus ratings}

Panel recommendations were derived from evidence within the published literature, as well as discussions during an in-person consensus meeting and regular communications and collaborative editing throughout the manuscript development process along with responses to a clinical questionnaire that addressed current practices in the use or recommendation for use of immunotherapy agents . Evidence supporting panel recommendations was graded according to the Oxford Center for EvidenceBased Medicine (OCEBM) Levels of Evidence (2016 version) ${ }^{26}$ A summary of the OCEBM grading scale may be found in table 1 . The level of evidence (LE) for a given consensus recommendation is expressed in parentheses following the recommendation (eg, LE: 1). Recommendations without an associated LE were based on expert consensus. Consensus was defined as $\geq 75 \%$ agreement among expert panel voting members.

\section{Conflict of interest policy}

As outlined by IOM standards, all financial relationships of expert panel member that might result in actual, potential, or perceived conflicts of interest were individually reported. Disclosures were made prior to the onset of manuscript development and updated on an annual basis. In addition, panel members were asked to articulate any actual or potential conflicts at all key decision points during guideline development, so that participants would understand all possible influences, biases, and/or the diversity of perspectives on the panel. Although some

\begin{tabular}{lllll}
\hline \multicolumn{4}{l}{ Table 1} & \multicolumn{4}{l}{ Summary of The Oxford Levels of Evidence 2 } & & \\
\hline Level 1 & Level 2 & Level 3 & Level 4 & Level 5 \\
\hline $\begin{array}{l}\text { Systematic review or } \\
\text { meta-analysis }\end{array}$ & $\begin{array}{l}\text { Randomized trial or } \\
\text { observational study } \\
\text { with dramatic effect }\end{array}$ & $\begin{array}{l}\text { Non-randomized } \\
\text { controlled cohort or } \\
\text { follow-up study }\end{array}$ & $\begin{array}{l}\text { Case series, case- } \\
\text { control or historically } \\
\text { controlled study }\end{array}$ & $\begin{array}{l}\text { Mechanism-based } \\
\text { reasoning }\end{array}$ \\
\hline
\end{tabular}

Adapted from OCEBM (Oxford Center for Evidence-Based Medicine) Levels of Evidence Working Group, "The Oxford Levels of Evidence 2."26 
degree of relationships without side interests among panel members are to be expected, those with any significant financial connections that may compromise their ability to fairly weigh evidence (either actual or perceived) were not eligible to participate.

Recognizing that guideline panel members are among the leading experts on the subject matter under consideration and guideline recommendations should have the benefit of their expertise, any identified potential conflicts of interests were managed as outlined in SITC's disclosure and conflict of interest resolution policies. As noted in these policies, panel members disclosing a real or perceived potential conflict of interest may be permitted to participate in consideration and decisionmaking of a matter related to that conflict, but only if deemed appropriate after discussion and agreement by the expert panel.

The financial support for the development of this guideline was provided solely by SITC. No commercial funding was received.

\section{GENERAL RECOMMENDATIONS}

\section{Product-specific and patient-specific considerations}

The onset and severity of therapy-associated toxicities typically correspond with the timing and degree of peak CAR $T$ cell activation and proliferation, as well as underlying disease. ${ }^{19}$ 27-32 Therefore, product and diseasespecific characteristics may place some patients at higher risk for adverse events. For the approved CAR $\mathrm{T}$ cell therapies, tisagenlecleucel, axicabtagene ciloleucel, and brexucabtagene autoleucel, structural differences in the costimulatory domains used to promote $\mathrm{T}$ cell activation have been implicated in the distinct risk profiles reported in trials to date. Both tisagenlecleucel and axicabtagene ciloleucel are based on identical antigen recognition domains (the anti-CD19 short-chain variable fragment FMC63), and both are constructed with identical CD3 $\zeta$ $\mathrm{T}$ cell signaling domains. Tisagenlecleucel deploys a $\mathrm{CD} 8 \alpha$ transmembrane region and a $4-1 \mathrm{BB}$ costimulatory domain, while axicabtagene ciloleucel and brexucabtagene autoleucel use a CD28 transmembrane region and a CD28 costimulatory domain. ${ }^{12}$ CD28-based CARs have been shown to induce rapid early expansion of $\mathrm{T}$ cells with boosted effector functions, whereas 4-1BB-based CARs cause a more gradual expansion of $\mathrm{T}$ cells, shifted toward a central memory-like phenotype, with a potential for longer persistence. ${ }^{33}$ The different signaling and expansion characteristics may explain the earlier timing of onset of adverse events that has been reported with CD28-containing CAR T cell therapies. ${ }^{35}$

In the pivotal ZUMA-1 trial, which led to the approval of axicabtagene ciloleucel, patients who had undergone prior allogeneic hematopoietic stem cell transplantation (allo-HSCT) were excluded, as were patients who had previously been treated with CAR T cells. Other exclusion criteria included central nervous system (CNS) involvement or a history of or active CNS disorder, such as seizure, cerebrovascular ischemia/hemorrhage, dementia, cerebellar disease, or any autoimmune disease with CNS involvement. ${ }^{24}$ In the ZUMA-2 trial that led to approval for brexucabtagene autoleucel for RR MCL, durable remissions were attained in the majority of patients, and the toxicities were similar to those observed with other CD28 costimulated products. ${ }^{1437}$ The JULIET trial, which was pivotal for the approval of tisagenlecleucel for the treatment of diffuse large B cell lymphoma (DLBCL), used similar criteria, with the addition of excluding patients with class III/IV cardiovascular disability according to the New York Heart Association Classification and patients in complete remission-although a history of prior CNS disease was allowed as long as no active involvement was present at the time of treatment. ${ }^{38}$ Subsequent trials have observed acceptable safety profiles for CAR T cell therapy in patients with active CNS disease-the phase I TRANSCEND NHL (Non-Hodgkin Lymphoma) 001 study, which evaluated lisocabtagene maraleucel, a CD19 CAR $\mathrm{T}$ cell product with defined $\mathrm{CD} 4^{+} / \mathrm{CD}^{+}$composition, reported only one neurological event among the nine treated patients with secondary CNS lymphoma. ${ }^{39} 40$

Current approvals only permit the use of CAR $\mathrm{T}$ cell therapies in patients with more advanced disease. However, relapse after complete remission is relatively common in both leukemia and lymphoma, and outcomes for these patients are generally poor. Based on the known mechanisms of CAR T cell therapies, patients with very low disease burden or in complete remission can likely be treated, potentially with greater safety, given the importance of disease burden as a risk factor for CRS. ${ }^{41-43}$

\section{Panel recommendations}

- Treatment decisions should be risk-adapted to take into account characteristics of individual patients and products, with earlier and more aggressive intervention warranted with higher risk.

- Patients who have previously undergone allo-HSCT, bispecific $\mathrm{T}$ cell engager (BiTE) therapy, anti-CD19 monoclonal antibody (mAb) therapy, and mAbs against other targets (eg, rituximab) may be treated with CAR T cells, provided the patient's disease still expresses the target antigen (LE: $4^{5}$ ).

- Consideration should be given to the fact that toxicity and timing of toxicities may differ, depending on the CAR T cell costimulatory domains or other structural components (LE: $4^{28}$ ).

- Patients with higher pretreatment disease burden are at increased risk of severe toxicity.

- Patient Eastern Cooperative Oncology Group (ECOG) performance status should be taken into account before proceeding with CAR T cell therapy, given the high risk of treatment-associated toxicity.

- If patients are treated with CAR T cell products in the outpatient setting, admission should be strongly considered at the first signs of toxicity, including fever, hypotension or altered mental status. 
- CAR T cell therapies may be appropriate for patients with stable oncological disease or in CR with high relapse risk (LE: $\left.4^{44}\right)$.

\section{Baseline evaluations before starting therapy}

The adverse events associated with FDA-approved CAR T cell therapies may develop suddenly and progress rapidly to life-threatening toxicities. As additional targets and indications expand the available repertoire of IEC therapies, the management of the toxicities associated with new products may require further modification. Regardless, establishing baseline values for markers of CRS and neurotoxicity is important so that the caregiving team can quickly recognize and respond to adverse events at the earliest possible onset. Several scoring systems have been developed to monitor baseline mental state, with the Immune Effector Cell-Associated Encephalopathy (ICE) score (a modified version of the CARTOX-10 criteria $^{25}$ ) being the most widely used for adult patients. ${ }^{45}$ For pediatric patients, the Cornell Assessment of Pediatric Delirium (CAPD),${ }^{46}$ has been validated for evaluating mental state after CAR T cell therapy ${ }^{47}$ Elevated C-reactive protein (CRP) and ferritin levels of $>10,000 \mathrm{ng} / \mathrm{mL}$ have been observed in almost every patient who developed severe CRS across public trials. It is important to note, however, that elevated levels of these markers are associated with, but not predictive of, toxicity. ${ }^{23} 48-52$

\section{Panel recommendations}

- Prior to CAR T cell therapy, treating physicians should order CRP, ferritin, lactate dehydrogenase (LDH), complete blood counts, comprehensive metabolic panel (including $\mathrm{Mg} / \mathrm{Pho}$ ), and transthoracic echocardiogram (TTE) or multigated acquisition (MUGA) scan. Required levels of these clinical parameters should be established by institutional standard operating parameters and are often similar to those required for a patient undergoing autologous hematopoietic stem cell transplantation (auto-SCT) (LE: $\left.4^{5053}\right)$.

- All patients should receive baseline neurological evaluations, including ICE scores (for adults) or CAPD scores (for children $<12$ years) prior to CAR $\mathrm{T}$ cell therapy (LE: $4^{51}$ ).

- Disease burden should be assessed via imaging and bone marrow evaluation and/or lumbar puncture, as appropriate, before initiating CAR T cell therapy.

- In the case of significant delay between lymphodepletion and infusion, repeating lymphodepleting chemotherapy should be considered after 4 weeks after initial lymphodepletion.

\section{Infection precautions and prophylaxis}

Immunosuppression secondary to lymphodepleting conditioning is an expected toxicity associated with CAR T cell therapy. Patients' immune defenses may be further compromised by on-target killing of B cells by CD19-targeting CAR T cell products, ${ }^{79555}$ as well as by emerging therapies such as BCMA-directed CAR T cells for multiple myeloma. Bacteremia, fungal infections, recurrent urinary tract infections, as well as viral infections such as influenza, respiratory syncytial virus, and herpes zoster have all been reported after CAR T therapy ${ }^{89243756-60}$ and reactivation of cytomegalovirus (CMV), Epstein-Barr virus (EBV), and human herpesvirus 6 are also of concern. In the ELIANA registration trial of tisagenlecleucel for children and young adults with RR ALL, infections occurred in $43 \%$ of patients, with $21 \%$ experiencing grade 3 and $3 \%$ grade 4 infections. In this trial, some patients with prolonged grade 3 or 4 neutropenia before and after tisagenlecleucel infusion experienced severe or fatal infections, including grade 3 human herpesvirus 6 encephalitis. ${ }^{23}$ A review of 133 patients with RR ALL, chronic lymphocytic leukemia (CLL), and NHL treated with CD19 CAR T cells observed that 26 patients $(23 \%)$ developed infections within 4 weeks of infusion and 19 (14\%) developed infections within 29-90 days after treatment. Bacterial infections were most common within the first 28 days, and viral infections occurred more frequently after day $29 .^{58}$ In the ZUMA-2 trial, infections of grade 3 or higher occurred in $32 \%$ of the patients, with the most common being pneumonia $(9 \%) .{ }^{14}$

Protocols vary from center to center for the routine administration of prophylactic antibacterial, antiviral, and antifungal agents for patients undergoing CAR T cell therapy. The US Centers for Disease Control and Prevention (CDC), together with the Infectious Diseases Society of America (IDSA) and ASTCT, has published guidelines for preventing infections in patients undergoing alloHSCT ${ }^{61-63}$ which apply to all myeloablative transplants regardless of recipient (adult or child). The published guidelines do not make a definitive statement on antibacterial prophylaxis, although the prospect of septicemia is a significant concern for patients undergoing CAR $\mathrm{T}$ cell therapy. A review of 31 centers with experience from approximately 3400 stem cell transplants found substantial heterogeneity in adherence to published guidelines, yet a majority of institutions use some form of antiviral prophylaxis, most often reflecting concern for latent CMV, herpes simplex virus (HSV), and varicella zoster virus (VZV) reactivation. ${ }^{64}$ Additional considerations for infection prevention in patients undergoing CAR $\mathrm{T}$ cell therapy may be found in a 2020 perspective from Hill and Seo. ${ }^{65}$

Patients with cancer are also at high risk of severe influenza-related complications, with a mortality rate 10 times higher than the general population. A Cochrane review of six studies with a total of 2275 participants found evidence, although weak, that the benefits of influenza vaccination outweigh potential risks in patients with cancer. ${ }^{456-68}$ However, patients with hematological malignancies frequently present with profound immunosuppression and cytopenias, both due to disease and prior therapies, which may limit the efficacy of 
seasonal influenza vaccines, especially in younger populations. ${ }^{69} 70$

Reports have emerged of two patients with HIV and RR DLBCL successfully being treated with axicabtagene ciloleucel. One patient was non-adherent to antiretroviral drugs prior to initiating therapy and underwent lymphodepletion with $\mathrm{CD} 4^{+}$cell counts of 53 cells $/ \mathrm{mm}^{3}$ and detectable viral load. After CAR T cell infusion, the patient developed grade 2 CRS and grade 3 ICANS, both of which resolved after tocilizumab and dexamethasone. The other patient was adherent with antiretroviral therapy (bictegravir, emtricitabine, and tenofovir alafenamide) with an undetectable HIV viral load and a CD4 count of 127 cells $/ \mathrm{mm}^{3}$. Both patients achieved complete remissions of their lymphoma after CAR T cell therapy. ${ }^{71}$ More experience is needed, however, to determine if HIV-positive patients are at increased risk of infections compared with other patients undergoing CAR $\mathrm{T}$ cell therapy.

\section{Panel recommendations}

The following recommendations are adapted for CAR T cell therapies from the US CDC, together with the IDSA and the ASTCT guidelines for preventing infections in patients undergoing allo-HSCT ${ }^{616267}$ :

- If a patient is febrile with positive bacterial blood cultures prior to infusion, appropriate antibacterial agents should be administered and CAR $\mathrm{T}$ cell infusion should be delayed until the patient is afebrile with negative cultures for at least 48 hours.

- If a fungal infection is suspected, lymphodepleting chemotherapy should not be administered until appropriate antifungals have been initiated and fungal infection is controlled.

- If nasal washes are positive for active viral infection (except for in cases of SARS-CoV-2, see next section) yet a patient is not in distress, then therapy may proceed when symptoms improve.

- All patients should undergo prophylaxis against pneumocystis pneumonia.

- Prophylaxis for HSV/VZV virus reactivation can be considered (ie, with low-dose acyclovir).

- The decision to administer antibacterial, antiviral, and/or antifungal prophylaxis should be risk-adjusted based on patient characteristics (ie, pediatric vs adult patients, prior lines of myelosuppresive therapy, and infection history).

- If patients have high-risk historical features, such as a history of prolonged steroid use or active highdose corticosteroid use, or are undergoing highdose lymphodepletion or anticytokine therapy, then antibacterial and antifungal prophylaxis should be strongly considered.

- All patients who develop persistent neutropenia should have antibacterial and antifungal prophylaxis.

- Patients with active influenza infections should be treated with antiviral therapy and infusion held until resolution of major symptoms.

\section{Special considerations for the SARS-CoV-2 pandemic}

The pandemic caused by the novel coronavirus SARS-CoV-2 has disrupted almost all aspects of the healthcare system, including cancer care. Treatment plans for patients undergoing CAR T cell therapies must take into account potential limitations in hospital resources during the ongoing pandemic, as well as an utmost concern for the safety of everyone involved. Because cellular therapy offers a potentially curative option for patients with otherwise extremely poor prognoses, delaying treatment may not be an option in many cases. However, adequate staff and supportive care resources are an absolute prerequisite for proceeding with CAR T cell therapy, and it is important to ensure that tocilizumab-which, along with other interleukin (IL)-6-modulating agents, was used as an investigational intervention for COVID-19-is available for the management of CRS. To assist in clinical decision making during the pandemic, the panel recommends referring to the interim guidelines published by the CAR T cell consortium investigators, which discuss necessary resources, determinants of cell therapy use, patient selection for B cell non-Hodgkin lymphomas and B cell ALL, supportive care measures during cell therapy administration, availability of tocilizumab doses for each patient during the CRS risk period, and collaborative care with referring physicians. ${ }^{72}$

\section{Grading adverse events}

Some of the most frequently seen adverse events associated with the FDA-approved CAR T cell therapies are CRS, with rates of occurrence ranging from $37 \%-93 \%$ in patients with lymphoma 243871 and $77 \%-93 \%$ in leukemia, 237374 and neurological toxicities, now referred to as ICANS, ${ }^{75}$ which have been reported in every trial involving CD19 targeted CAR T cells. ${ }^{76}$ Early trials frequently deployed different assessment and grading criteria, making it difficult to compare the incidence and severity of CRS and other adverse events across studies. For example, in the National Cancer Institute's Common Terminology Criteria for Adverse Events (CTCAE) V.4.03, which was in effect when most CAR $T$ trials began, fever was not included as a prerequisite for CRS and grading largely depended on whether infusion was interrupted, ${ }^{77}$ which is not applicable for CAR T cells that are normally given as a single dose over less than $30 \mathrm{~min}$. Several grading systems, including the Lee Criteria, Penn Criteria, and CARTOX Criteria, were developed, defining severity by the requirement for supplemental oxygen and the need for intravenous fluids and vasopressors. ${ }^{28} 59$ 78-80 Until recently, neurological events were considered to be a component of CRS. However, although severe neurotoxicity seems to exclusively affect patients who develop CRS, the timing can vary greatly, occurring concomitantly or days after CRS resolves. ${ }^{5156}$ In 2019, the ASTCT published consensus recommendations for separate grading systems for CRS and ICANS (tables 2-4). ${ }^{75}$ Advantages to the ASTCT system are its ease of use, objectivity, solid basis on criteria that may be immediately assessed by all members 
Table 2 ASTCT CRS consensus grading (adapted from Lee et al/ASTCT, BBMT, 2019 ${ }^{75}$ )

\begin{tabular}{|c|c|c|c|c|}
\hline CRS parameter & Grade 1 & Grade 2 & Grade 3 & Grade 4 \\
\hline Fever $^{*}$ & Temperature $\geq 38^{\circ} \mathrm{C}$ & Temperature $\geq 38^{\circ} \mathrm{C}$ & Temperature $\geq 38^{\circ} \mathrm{C}$ & Temperature $\geq 38^{\circ} \mathrm{C}$ \\
\hline \multicolumn{5}{|l|}{ With } \\
\hline
\end{tabular}

Organ toxicities associated with CRS may be graded according to CTCAE V.5.0, but they do not influence CRS grading.

${ }^{*}$ Fever is defined as a temperature of $\geq 38^{\circ} \mathrm{C}$ not attributable to any other cause. In patients who have CRS who then undergo antipyretic or anticytokine therapy such as tocilizumab or steroids, fever is no longer required to grade subsequent CRS severity. In this case, CRS grading is driven by hypotension and/or hypoxia.

TCRS grade is determined by the more severe event: hypotension or hypoxia not attributable to any other cause. For example, a patient with a temperature of $39.5^{\circ} \mathrm{C}$, hypotension requiring one vasopressor, and hypoxia requiring low-flow nasal cannula is classified as grade $3 \mathrm{CRS}$. ASTCT, American Society for Transplantation and Cellular Therapy; CRS, cytokine release syndrome.

of a caregiving team, and accuracy in categorizing the severity of toxicities, although disadvantages include dependence on the selected interventions for grading.

Retrospective analysis of CRS grading systems demonstrated some alignment between the ASTCT and Lee criteria, in addition to ASTCT versus Penn criteria, while there were notable differences between Penn and Lee criteria. Similarly, the CTCAE neurotoxicity grading and ASTCT ICANS grading are quite different, with retrospective grading demonstrating key areas of disagreement. ${ }^{81}$

Table 3 ASTCT ICANS consensus grading for adults (adapted from Lee et al/ASTCT, BBMT, 201975)

\begin{tabular}{|c|c|c|c|c|}
\hline $\begin{array}{l}\text { Neurotoxicity } \\
\text { domain }\end{array}$ & Grade 1 & Grade 2 & Grade 3 & Grade 4 \\
\hline ICE score* & $7-9$ & $3-6$ & $0-2$ & 0 (patient is unarousable) \\
\hline $\begin{array}{l}\text { Depressed level of } \\
\text { consciousness } †\end{array}$ & $\begin{array}{l}\text { Awakens } \\
\text { spontaneously }\end{array}$ & $\begin{array}{l}\text { Awakens to } \\
\text { voice }\end{array}$ & $\begin{array}{l}\text { Awakens only to tactile } \\
\text { stimulus }\end{array}$ & $\begin{array}{l}\text { Patient is unarousable or requires vigorous } \\
\text { or repetitive tactile stimuli to arouse; stupor } \\
\text { or coma }\end{array}$ \\
\hline Seizure & $\mathrm{N} / \mathrm{A}$ & $\mathrm{N} / \mathrm{A}$ & $\begin{array}{l}\text { Any clinical seizure } \\
\text { focal or generalized that } \\
\text { resolves rapidly or non- } \\
\text { convulsive seizures on } \\
\text { EEG that resolve with } \\
\text { intervention }\end{array}$ & $\begin{array}{l}\text { Life-threatening prolonged seizure ( }>5 \mathrm{~min} \text { ), } \\
\text { repetitive clinical or electrical seizures } \\
\text { without return to baseline in between }\end{array}$ \\
\hline Motor findings $\ddagger$ & $\mathrm{N} / \mathrm{A}$ & $\mathrm{N} / \mathrm{A}$ & N/A & $\begin{array}{l}\text { Deep focal motor weakness such as } \\
\text { hemiparesis or paraparesis }\end{array}$ \\
\hline $\begin{array}{l}\text { Elevated ICP/ } \\
\text { cerebral edema }\end{array}$ & $\mathrm{N} / \mathrm{A}$ & $\mathrm{N} / \mathrm{A}$ & $\begin{array}{l}\text { Focal/local edema on } \\
\text { neuroimaging§ }\end{array}$ & $\begin{array}{l}\text { Diffuse cerebral edema on neuroimaging, } \\
\text { decerebrate or decorticate posturing, } \\
\text { cranial nerve VI palsy, papilledema, or } \\
\text { Cushing's triad }\end{array}$ \\
\hline
\end{tabular}

ICANS grade is determined by the most severe event not attributable to any other cause.

${ }^{*}$ A patient with an ICE score of 0 may be classified as grade 3 ICANS if awake with global aphasia, but a patient with an ICE score of 0 may be classified as grade 4 ICANS if unarousable.

†Attributable to no other cause (eg, no sedating medication).

†Tremors and myoclonus associated with immune effector cell therapies may be graded according to CTCAE V.5.0, but they do not influence ICANS grading.

§Intracranial hemorrhage with or without associated edema is not considered a neurotoxicity feature and is excluded from ICANS grading. It may be graded according to CTCAE V.5.0.

ASTCT, American Society for Transplantation and Cellular Therapy; CTCAE, Common Terminology Criteria for Adverse Events; EEG, electroencephalogram; ICANS, immune effector cell-associated neurotoxicity syndrome; ICE, Effector Cell-Associated Encephalopathy; ICP, intracranial pressure; N/A, not applicable. 
Table 4 ASTCT ICANS consensus grading for children (adapted from Lee et al. ${ }^{75}$ )

\begin{tabular}{|c|c|c|c|c|}
\hline $\begin{array}{l}\text { Neurotoxicity } \\
\text { domain }\end{array}$ & Grade 1 & Grade 2 & Grade 3 & Grade 4 \\
\hline $\begin{array}{l}\text { ICE score (age } \geq 12 \\
\text { years)* }\end{array}$ & $7-9$ & $3-6$ & $0-2$ & 0 (patient is unarousable) \\
\hline $\begin{array}{l}\text { CAPD score (age } \\
<12 \text { years) }\end{array}$ & $1-8$ & $1-8$ & $\geq 9$ & Unable to perform CAPD \\
\hline $\begin{array}{l}\text { Depressed level of } \\
\text { consciousness } \dagger\end{array}$ & $\begin{array}{l}\text { Awakens } \\
\text { spontaneously }\end{array}$ & $\begin{array}{l}\text { Awakens to } \\
\text { voice }\end{array}$ & $\begin{array}{l}\text { Awakens only to tactile } \\
\text { stimulus }\end{array}$ & $\begin{array}{l}\text { Unarousable or requires vigorous or } \\
\text { repetitive tactile stimuli to arouse }\end{array}$ \\
\hline Seizure (any age) & $\mathrm{N} / \mathrm{A}$ & $\mathrm{N} / \mathrm{A}$ & $\begin{array}{l}\text { Any clinical seizure focal or } \\
\text { generalized that resolves } \\
\text { rapidly or non-convulsive } \\
\text { seizures on EEG that resolve } \\
\text { with intervention }\end{array}$ & $\begin{array}{l}\text { Life-threatening prolonged seizure } \\
\text { ( }>5 \mathrm{~min}) \text {, repetitive clinical or electrical } \\
\text { seizures without return to baseline in } \\
\text { between }\end{array}$ \\
\hline $\begin{array}{l}\text { Motor weakness } \\
\text { (any age) } \ddagger\end{array}$ & N/A & $\mathrm{N} / \mathrm{A}$ & $\mathrm{N} / \mathrm{A}$ & $\begin{array}{l}\text { Deep focal motor weakness such as } \\
\text { hemiparesis or paraparesis }\end{array}$ \\
\hline
\end{tabular}

ICANS grade is determined by the most severe event not attributable to any other cause. Baseline ICE or CAPD score should be considered before attributing to ICANS.

${ }^{*} A$ patient with an ICE score of 0 may be classified as grade 3 ICANS if awake with global aphasia, but a patient with an ICE score of 0 may be classified as grade 4 ICANS if unarousable.

†Attributable to no other cause (eg, no sedating medication).

¥Tremors and myoclonus associated with immune effector cell therapies may be graded according to CTCAE V.5.0, but they do not influence ICANS grading.

§Intracranial hemorrhage with or without associated edema is not considered a neurotoxicity feature and is excluded from ICANS grading. It may be graded according to CTCAE V.5.0.

ASTCT, American Society for Transplantation and Cellular Therapy; CTCAE, Common Terminology Criteria for Adverse Events; EEG, electroencephalogram; ICANS, immune effector cell-associated neurotoxicity syndrome; ICE, Effector Cell-Associated Encephalopathy; ICP, intracranial pressure; N/A, not applicable.

As such, interpretation of published CRS and ICANS incidence and severity data must always take into account the grading system used.

\section{Panel recommendation}

- The ASTCT consensus system should be used to grade CRS and ICANS within IEC clinical trials, as well as after the use of tisagenlecleucel, axicabtagene ciloleucel, and brexucabtagene autoleucel.

\section{CYTOKINE RELEASE SYNDROME}

CRS is the most common adverse event reported across all CAR T cell clinical trials, with an incidence as high as $74 \%-100 \%$ for CD19-directed products. ${ }^{23} 27385759$ CRS is characterized by elevated serum cytokine levels associated with $\mathrm{T}$ cell activation and proliferation. It is considered an on-target toxicity, arising due to antigen recognition by IECs, followed by generalized immune activation, which often includes features of a macrophage activation syndrome (MAS). ${ }^{79}$ Emerging data suggest that monocytes and macrophages contribute to the development of CRS. ${ }^{82} 83$ Initial aspects of CRS pathophysiology, including the importance of IL- 6 , have been initially characterized after CAR T cell therapies, ${ }^{750}$ but different mechanisms may be implicated with other IEC therapies.
Several descriptions of treatment strategies for CAR T cell-associated CRS have been published. ${ }^{52128313552598084-87}$ Although the vast majority of published data has arisen from experience with tisagenlecleucel and axicabtagene ciloleucel, CRS has also been observed and treated in emerging CAR $\mathrm{T}$ cell products, such as the BCMAtargeting bb2121 ${ }^{88}$ and JNJ-4528. Generally, treatment of CRS encompasses vigilant supportive care, combined with therapies intended to break the cycle of aberrant inflammation.

\section{Laboratory parameters and baseline tests for CRS}

Patients with CRS frequently present with elevated serum CRP and ferritin; however, many standard markers (including ferritin, CRP, LDH, aspartate aminotransferase, alanine aminotransferase, and creatinine) may only reach abnormal levels after the onset of clinical manifestations of CRS. ${ }^{50}$ Although not typically reported in clinical charts, the hallmark cytokines of CRS associated with CD19-directed CAR T therapies are IL-10, IL-6, and interferon gamma (IFN- $\gamma){ }^{2150} 597885878990$ Other markers of inflammation, including tumor necrosis factor alpha $(\mathrm{TNF}-\alpha)$ and granulocyte macrophage colony-stimulating factor (GM-CSF), have also been observed at elevated 
levels in patient serum. ${ }^{508590}$ Inhibition of GM-CSF has also been demonstrated to ameliorate CRS pathology in xenograft models of leukemia. ${ }^{82}$ A recent effort to identify risk-associated biomarkers determined that none of the standard clinical laboratory tests were predictive of CRS severity. That study developed a three-cytokine signature, based on samples drawn in the first 72 hours, using IFN- $\gamma$, soluble gp130, and soluble IL-1 receptor antagonist, which enabled accurate prediction of which patients with ALL developed grade 4-5 CRS with $86 \%$ sensitivity (95\% CI $57 \%$ to $98 \%$ ) and $89 \%$ specificity (95\% CI $73 \%$ to $97 \%$ ). In pediatric patients, a signature based on IFN- $\gamma$, IL-13, and the macrophage inflammatory protein MIP1 $\alpha$ in samples drawn within the first 72 hours after treatment predicted grade 4-5 CRS with $100 \%$ sensitivity (95\% CI $72 \%$ to $100 \%)$ and $96 \%$ specificity $(95 \%$ CI $81 \%$ to $100 \%) .{ }^{50}$ Because real-time monitoring of cytokine levels is typically unavailable in most treatment centers, most grading systems (including the ASTCT consensus grading system $^{75}$ ) are based on clinical observations.

\section{Panel recommendations}

- In the inpatient setting, complete blood counts, comprehensive metabolic panel (CMP), Mg, Phos, CRP, and ferritin should be ordered daily for patients treated with CAR T cell therapies. Fibrinogen and uric acid should also be monitored, as required (LE: $3^{50}$ ).

- Neither cytokine levels nor CRP levels have been validated to be used for clinical decision making for patients treated with CAR $\mathrm{T}$ cell therapies.

- In patients with prolonged severe CRS (persisting for 72 hours without response to interventions), a cardiac assessment should be considered as described in the cardiology section; this may include measurement of cardiac biomarkers such as troponin or the performance of a TTE (LE: $\left.4^{91}\right)$.

- Consider holding G-CSF during CRS. GM-CSF should be avoided during CRS. Additional recommendations for the use of growth factors may be found in the cytopenias section (LE: $5^{8283}$ ).

\section{Clinical signs and symptoms for identification of CRS}

Per the ASTCT grading system (table 2), fever defines the onset of CRS, with a temperature $\geq 38^{\circ} \mathrm{C}$ not attributable to any other cause being the sole symptom required for classification as grade 1 . Although fever defines the onset, if patients are treated with antipyretics or anticytokine therapy, elevated temperature is not required for subsequent grading, and hypotension and hypoxia are used to assess severity. At grade 2 CRS, patients present with hypotension not requiring vasopressors and/or hypoxia requiring low-flow nasal cannula $(\leq 6 \mathrm{~L} / \mathrm{min})$ or blow-by oxygen. Hypotension requiring a vasopressor (with or without vasopressin) and/or hypoxia necessitating highflow ( $>6 \mathrm{~L} / \mathrm{min}$ ) nasal cannula, face mask, non-rebreather or venturi mask defines grade 3 CRS. At grade 4, patients need multiple vasopressors (again, excluding vasopressin) and/or positive pressure ventilation up to and including intubation. Grade 5 CRS is defined as death in which another cause is not the principle factor. Resolution is defined by the normalization of all signs and symptoms that led to the diagnosis of CRS. In patients treated with anticytokine therapy whose temperatures have come down, CRS may be downgraded as hypotension and hypoxia improves. ${ }^{75}$

Beyond fever, hypotension and hypoxia, symptomology varies widely. CRS symptoms may resemble tumor lysis syndrome (TLS), ${ }^{90} 92$ or at higher grades, the clinical presentation can mimic infection, with malaise, fatigue, anorexia, myalgias, nausea, vomiting, headache, and mental status changes. ${ }^{20} 2127597578808790$ Myalgias and headaches are extremely common. ${ }^{93}{ }^{94}$ Since CRS and sepsis can coexist, it is very important to presume patients are infected and managed accordingly while investigating underlying infections in patients undergoing IEC therapies.

\section{Panel recommendations}

- After CAR T cell infusion, patients should be monitored for CRS and other toxicities for the duration recommended by the product package insert or study protocol (typically several weeks).

- Clinical assessment for CRS should be performed on an ongoing basis by all members of a patient's caregiving team. Grading of CRS should be performed when a patient's clinical status changes.

- Events requiring physician notification should include deviations from baseline in systolic blood pressure, heart rate of $>120$ or $<60$ beats $/ \mathrm{min}$, arrhythmia, respiratory rate of $>25$ or $<12$ breaths/min (or values outside the normal range in pediatric patients), arterial oxygen saturation of $<92 \%$ on room air, upward trend in blood creatinine levels or liver function tests, tremors or jerky movements in extremities, altered mental status, and first occurrence of temperature greater than $38^{\circ} \mathrm{C}$, as per the ASTCT definition of fever.

\section{Timing of onset for CRS}

Typically, CRS occurs within 1-2 weeks of cell administration. ${ }^{28}$ Peak signs and symptoms have been reported to correlate with maximal CAR $\mathrm{T}$ cell proliferation. For tisagenlecleucel and axicabtagene ciloleucel, the median time to onset is $2-3$ days but can be as early as within 24 hours, particularly with axicabtagene ciloleucel. Notably, the time to onset of fever may be earlier in patients treated with CD28- (ie, axicabtagene ciloleucel and brexucabtagene autoleucel) compared with 4-1BBcostimulated (ie, tisagenlecleucel) CAR T cell products. ${ }^{35}$ Most cases of CRS resolve within 7-8 days of the onset of symptoms, but cases have been documented that persist more than 30 days. ${ }^{95}$ The package inserts for Yescarta (axicabtagene ciloleucel) and Tecartus (brexucabtagene autoleucel) mandate 7 days of daily monitoring after infusion, whereas Kymriah (tisagenlecleucel) may be administered in the outpatient setting, provided patients are 
monitored two to three times during the first week after infusion. Patients or their caregivers need to have a thermometer available to monitor and report any fever. Both products advise patients to remain within a 2-hour drive of their treatment center for 4 weeks, ${ }^{1-3}$ and the clinical infrastructure and communications need to be clear and able to expeditiously admit and evaluate a patient post-CAR $\mathrm{T}$ who reports a fever.

\section{Panel recommendations}

- Product labeling, product-specific risk evaluation and mitigation strategies (REMS), and trial-specific guidelines should inform the duration and frequency of monitoring after infusion.

- In patients deemed to be at high risk of developing CRS (see next section), inpatient treatment and/or more frequent monitoring may be warranted.

- As centers gain more experience administering CAR $\mathrm{T}$ cell therapies, requirements for monitoring may be modified and outpatient administration may be initiated with the best judgment of the treating physician.

- Cellular therapy centers should educate patients and a primary caregiver regarding typical manifestations of CRS, and about specific actions to take if signs or symptoms occur.

\section{Increased risk factors for CRS}

Across several trials, the most important predictor of severe CRS after CAR T therapy has been disease burden. ${ }^{41609096}$ A retrospective single-center study of 98 children with ALL treated with tisagenlecleucel found that pretreatment blast count of $>25 \%$ increased the risk for hypotension-requiring inotropic support. In the study, pre-existing cardiac risk factors, systolic or diastolic dysfunction, or pre-existing ECG abnormalities were also risk factors. ${ }^{97}$ Higher doses of CAR T cells and CARs containing CD28 costimulatory domains are also associated with increased risk. ${ }^{49} 579596$

\section{Panel recommendations}

- High prelymphodepletion disease burden and products that are known to be associated with robust early expansion of CAR $\mathrm{T}$ cells are known risk factors for severe CRS (LE: $3^{56}$ ).

- Clinical decisions should be based on the expected course of CRS with the products being used and the patient being treated.

\section{Management of CRS}

Management of CRS often involves direct targeting of elevated cytokines, especially IL-6. The IL-6 receptorblocking antibody tocilizumab was approved by the FDA in 2017 for the treatment of severe or life-threatening CAR T-induced CRS. ${ }^{98}$ However, some protocols advise administering tocilizumab at earlier onset. A treatment algorithm developed from experience with the axicabtagene ciloleucel clinical trials advised considering $8 \mathrm{mg}$ / $\mathrm{kg}$ intravenous tocilizumab for persistent (lasting $>3$ days) and refractory fever in grade 1 CRS, and anti-IL-6 therapy is recommended for managing hypotension, hypoxia, and organ toxicity at all grade 2 and higher cases. ${ }^{28}$ CRS management for brexucabtagene autoleucel in ZUMA-2 was similar to previous experience from antiCD19 CAR T cells that have CD28 and CD3 $\zeta$ costimulatory domains. ${ }^{14}$ During the tisagenlecleucel clinical trials, early CRS symptoms were managed with tocilizumab, and corticosteroids were only used as secondline therapy, in case of refractory hypotension or other severe CRS symptoms not responsive to the first dose of tocilizumab. ${ }^{80}$ Methylprednisolone $(2 \mathrm{mg} / \mathrm{kg} /$ day $)$ and dexamethasone $(0.5 \mathrm{mg} / \mathrm{kg}$; maximum, $10 \mathrm{mg} /$ dose $)$ are both commonly used corticosteroids. Some protocols, in particular those with CD19-directed CAR T cell therapies with CD28 signaling domains, recommend using dexamethasone for patients with neurological symptoms due to more efficient penetration of the blood-brain barrier. Many patients, especially those with ALL or multiple myeloma, have received corticosteroids as part of their treatment regimen, and therefore some patients who experience CRS may have a relative corticosteroid deficiency due to suppression of their hypothalamic-pituitary axis. ${ }^{59}$ High-dose steroids are not recommended as a first steroid therapy, as $>100 \mathrm{mg}$ daily of prednisone equivalent may reverse symptoms but risks concurrently ablating 19-28z CAR T cells. ${ }^{79}$

Consideration has been given to using tocilizumab preemptively or as prophylaxis. The Fred Hutchinson Cancer Research Center, Seattle group reported early administration of tocilizumab with and without dexamethasone after treatment with a 4-1BB secondgeneration CAR $\mathrm{T}$ cell product with encouraging data of a modest decrease in severe CRS. ${ }^{99}$ A similar clinical trial at Children's Hospital of Philadelphia prospectively tested a preemptive approach in pediatric ALL patients with high disease burden ( $>40 \%$ marrow blasts), giving tocilizumab at the time of fever. This preemptive trial met the endpoint for grade 4 CRS reduction (by one-third) in these high-risk patients. ${ }^{100}$

Other cytokine-directed therapies, such as siltuximab, a chimeric anti-IL-6 mAb, have occasionally been used in the management of CRS. ${ }^{24} 85$ Based on preclinical models and known cytokine profiles, anti-IL-1 therapies, such as anakinra, have been proposed for CRS treatment, but data are lacking regarding their efficacies in humans. ${ }^{93}$ Reports have emerged of patients presenting with atypical, tocilizumab-refractory CRS, characterized by early increases in GM-CSF and IL-2, ${ }^{101}$ highlighting a need for alternate approaches. In cases of CRS that do not respond to 2 to 3 doses of tocilizumab, benefit with additional doses is unclear. Additionally, a retrospective analysis of 100 patients with RR large B cell lymphoma treated with axicabtagene ciloleucel found a trend for shorter progression-free survival (PFS) among patients receiving corticosteroids for a prolonged time. ${ }^{102}$ 
Panel recommendations

- For elderly patients or patients with extensive comorbidities, tocilizumab should be considered earlier in the course of CRS.

- For adults who develop ASTCT grade 2 CRS, tocilizumab may be considered (LE: $3^{98}$ ).

- For pediatric patients, tocilizumab should be administered at ASTCT grade 3 CRS (LE: $3^{7}$ ).

- For pediatric patients who develop prolonged ASTCT grade 2 CRS or intolerance to fever, tocilizumab may be administered (LE: $4^{7}$ ).

- In both adults and children, if CRS does not improve after 1 dose of tocilizumab, then steroids should be administered with a second dose of tocilizumab (LE: $\left.3^{213152}\right)$.

- If CRS does not improve after 2 doses of tocilizumab (and steroids), third-line agents, including anakinra, siltuximab, and high-dose methylprednisolone, should be considered (LE: $4^{996}$ ).

- If CRS does not improve after tocilizumab and steroids, infections should be considered again in the differential diagnosis and managed appropriately.

- If steroids are used in the management of CRS, a rapid taper should be used once symptoms begin to improve.

\section{HLH/MAS-LIKE TOXICITY}

The spectrum of clinical features and laboratory abnormalities seen in CRS overlap substantially with HLH and MAS. ${ }^{50}$ In these cases, the MAS features usually respond to CRS therapy. In addition, reports have emerged of patients developing fulminant inflammatory coagulopathies with clinical features similar to grade 3 or 4 CRS characterized by high fevers, elevated ferritin levels, increased liver enzymes, and persistent pancytopenias later, even weeks, after CAR T cell infusion. ${ }^{103}$ Because of the atypical timing of onset and observations that these late CRS events may not respond to tocilizumab, in these later events MAS may predominate. ${ }^{5085} \mathrm{HLH} / \mathrm{MAS}$ is a potentially life-threatening dysfunctional immune response characterized by hyperactive macrophages and lymphocytes, proinflammatory cytokine hypersecretion, tissue infiltration, hemophagocytosis, and organ damage. Primary HLH is an autosomal recessive genetic disease with an incidence of roughly 1 in 100,000 live births, and a median survival of less than 2 months without treatment. The more common, though still rare, presentation is secondary, or reactive, HLH or MAS, which may be triggered by infections (especially EBV, CMV, and HIV), autoimmune diseases, and cancers. HLH is believed to occur in as many as $1 \%$ of patients with hematological malignancies, and mortality rates associated with $\mathrm{HLH}$ secondary to cancer approach $80 \%{ }^{103}$

Most patients with moderate to severe CRS have laboratory results that meet the classic criteria for HLH/MAS, including elevated serum levels of IFN $\gamma$, IL-10, sIL-2R $\alpha$, IL-6, IL-8, and GM-CSF, ${ }^{28} 5085$ but may or may not have hepatosplenomegaly, lymphadenopathy, or overt evidence of hemophagocytosis. CRS and HLH/MAS substantially overlap clinically; therefore, using clinical management guidelines for CRS initially when HLH/MAS is suspected is warranted. The management of late-onset severe CRS may be challenging, especially if tocilizumab does not resolve symptoms. Treatment of bona fide HLH/MAS typically involves cytotoxic chemotherapy, such as etoposide. ${ }^{104}$ This approach is not recommended for patients undergoing CAR T cell therapy, due to etoposide's documented toxicity to T lymphocytes ${ }^{105} 106$ and lack of data in this setting. ${ }^{103}$ Anecdotal reports have surfaced of successful resolution of symptoms after anakinra administration $^{107}$; however, no prospective studies document the efficacy of any one specific intervention.

\section{Panel recommendations}

- CRS and HLH/MAS substantially overlap.

- However, late-onset, tocilizumab-refractory HLH/ MAS-like symptoms may represent a distinct and separate pathology than conventional CRS (LE: $4^{108}$ ).

- Delayed coagulopathy may possibly be one hallmark of delayed onset HLH/MAS-like toxicity, typically hypofibrinogenemia disproportionately worse than changes in PT/PTT, which requires close follow-up and replacement with cryoprecipitate (LE: $\left.4^{103}{ }^{108}\right)$.

- Etoposide should only be administered to patients experiencing late-onset, tocilizumab-refractory HLH/ MAS-like symptoms after CAR $\mathrm{T}$ cell therapy as a last resort (LE: $4^{103}$ ).

- For treatment of late-onset, HLH/MAS-like pathology, which may be tocilzumab-refractory, third-line CRS agents such as anakinra and steroids may be considered (LE: $4^{83107}$ ).

\section{IMMUNE EFFECTOR CELL-ASSOCIATED NEUROTOXICITY SYNDROME}

Transient neurological complications have been reported in nearly every trial targeting T cells to CD19, including studies involving CAR T cells and BiTEs. ${ }^{76}$ The likelihood of neurological toxicity may vary depending on the product and disease state. For example, the reported incidence of neurological toxicities is $87 \%$ for axicabtagene ciloleucel. ${ }^{1}$ For tisagenlecleucel, neurological toxicity was reported in $72 \%$ of patients with RR ALL and $58 \%$ of patients with RR DLBCL. ${ }^{2}$ Although fewer patients have been treated with the BCMA-targeting CAR $\mathrm{T}$ product bb2121, the rate of neurotoxicity in a phase I trial was $42 \%$, with only one patient experiencing toxicity $\geq$ grade $3{ }^{16}$ The frequency of neurological events has been rare in trials for the treatment of solid tumors, such as in a phase I/II clinical study of a HER2-specific CAR T therapy, where no neurotoxicity was reported among all 19 patients. ${ }^{109}$ However, efficacy of IEC in solid tumors has been more limited, and it is possible that the incidence of ICANS may increase with the development of more efficacious products.

Although the ASTCT consensus guidelines include elevated intracranial pressure and edema as domains 
for ICANS grading (see and tables 3 and 4), it is unclear whether cerebral edema arises from a distinct pathophysiology. ${ }^{75}$ Reports have emerged of lethal cerebral edema after treatment with CD19-directed CAR $\mathrm{T}$ cells in six patients across two different studies, ${ }^{11}{ }^{36}$ another fatal case in the standard of care setting, ${ }^{110}$ as well as one case of reversible cerebral edema in a patient receiving BCMAtargeting CAR T cells. ${ }^{111}$

The pathophysiology behind ICANS is an active area of investigation. Current hypotheses hold that systemic inflammation and cytokine production after CAR $\mathrm{T}$ cell infusion drives a cascade of endothelial cell activation and blood-brain barrier disruption, leading to elevated cytokine levels in the cerebral spinal fluid (CSF), and, in severe cases, hemorrhage and cerebral edema. ${ }^{27} 485156$ Across multiple studies, patients who developed severe ICANS exhibited higher serum levels of proinflammatory cytokines, such as IL-2 and IL-15 as well as cytokines known to activate endothelial cells, including IL- 6 , IFN- $\gamma$, and TNF-o. ${ }^{9} 232427485156$ Importantly, IL-6 receptor blockade is generally considered not effective for resolving neurological symptoms. ${ }^{22} 7595$

Severe ICANS is often associated with a consumptive coagulopathy and patients display elevated serum levels of laboratory markers of endothelial dysregulation including von Willebrand factor (vWF), which is released on endothelial cell activation, and angiopoietin 2 (ANG2), which is a TIE2 antagonist that shifts the balance of endothelial cells in the blood-brain barrier away from quiescence. ${ }^{48557}$ The elevated levels of cytokines, including IL-6, seen in the CSF of patients with severe ICANS likely arise due to both blood-brain barrier permeability and local production by activated microglia, astrocytes, and macrophages, and the relative contribution of each cell type remains unclear. ${ }^{2748515256}$ Trafficking of T cells into the CNS may play some role in the neuropathology, as indicated by the detection of CAR T cells in CSF from patients with neurotoxicity in the absence of malignant CNS disease. Yet CAR T cells have also been detected in CSF of patients with no detectable neurological pathology, demonstrating that infiltration alone is not sufficient to cause toxicity. ${ }^{79112113}$

\section{Laboratory parameters, baseline tests for ICANS}

Several of the cytokine profiles and serum markers associated with ICANS overlap with CRS. During the ZUMA-1 study, severe neurotoxicity was associated with elevated levels of IL-1R $\alpha$, IL-2R $\alpha$, IL-6, IL-8, IL-10, IL-15, IFN- $\gamma$, CCL-2, granzyme B, GM-CSF, and ferritin. ${ }^{114}$ Similarly, elevated levels of IL-1 $\alpha$, IL-2, IL-3, IL-5, IL-6, IL-10, IL-15, IFN- $\gamma$, G-CSF, GM-CSF, and MCP1 were observed in the 33 of 53 adult patients with RR B-ALL who developed neurotoxicity during phase I trials of 19-28z CAR T cells. ${ }^{51}$ A study encompassing 133 patients with relapsed B cell malignancies reported elevated CRP, ferritin, IL-6, IL-8, MCP1, IFN- $\gamma$, and TNF- $\alpha$ in the 53 patients who developed ICANS. ${ }^{57}$ Markers of diffuse intravascular coagulation have also been correlated with high-grade neurotoxicity, with two studies reporting elevated vWF and high ANG2:ANG1 ratios in patients with severe ICANS. $^{.156}$

Prior to infusion, patients should be evaluated for baseline neurological and mental status. The ASTCT consensus grading system for ICANS (see tables 2 and 3) deploys a 10-point scoring metric called the ICE tool ${ }^{75}$ for ICANS-associated encephalopathy in adults, which builds and simplifies the assessment items developed in the CARTOX criteria. ${ }^{28}$ Points are assigned for orientation to year, month, city, and hospital, ability to name three objects, ability to follow simple commands, ability to write a standard sentence, and ability to count backwards from 100 by 10 . For pediatric patients, the CAPD is used. ${ }^{75}$

\section{Panel recommendations}

- To monitor neurological function in patients treated with CAR T cell therapy, the ASTCT ICANS grading system and criteria should be used.

- For patients who develop ICANS, the work-up should include CRP, CBC, CMP, fibrinogen, prothrombin time test, and international normalized ratio (PT/ INR). A head CT should also be considered. In addition, careful consideration of electroencephalogram (EEG) and neuroimaging by brain MRI may be necessary (LE: $\left.4^{51}\right)$.

\section{Increased risk factors upon assessment}

Across studies the most consistent factors associated with the development of neurotoxicity have been disease burden and peak CAR $\mathrm{T}$ cell expansion. ${ }^{5156114}$ Classification tree modeling from the Fred Hutchinson Cancer Research Center study demonstrated that patients with fever of $\geq 38.9^{\circ} \mathrm{C}$ and serum IL- 6 of $\geq 16 \mathrm{pg} / \mathrm{mL}$ and MCP- 1 of $\geq 1343.5 \mathrm{pg} /$ $\mathrm{mL}$ in the first 36 hours after CAR $\mathrm{T}$ cell infusion were at high risk of subsequent grade $\geq 4$ neurotoxicity (sensitivity $100 \%$; specificity $94 \%$ ).$^{56}$ Other risk factors include extramedullary disease, ${ }^{51}$ younger age, pre-existing neurological comorbidities, higher total CAR T cell doses, and cytopenias. ${ }^{56}$ High-grade CRS is associated with a greater risk of ICANS. ${ }^{23}$ Although real-time serum cytokine monitoring is typically unavailable outside a few academic centers, several biomarkers have been significantly associated with neurological adverse events, including IL-6, IL-10, IL-15, IL-2R $\alpha$, and granzyme B. ${ }^{24}$ Fludarabinecontaining conditioning regimens have been raised as a concern, ${ }^{56}$ and initially fludarabine was thought to have increased the risk of lethal cerebral edema during the ROCKET trial of JCAR015. ${ }^{115}$ This was not borne out, because additional deaths occurred with a modified lymphodepletion regimen. Because the neurological symptoms and timing of onset associated with fludarabine are distinct from those seen with CD19 CAR T neurotoxicity, the agent has now come to be broadly recognized as not a primary driver for ICANS. ${ }^{97}$ More likely, the addition of fludarabine may 
have contributed indirectly to greater baseline lymphopenia and consequent further expansion of CAR $\mathrm{T}$ cells mediating toxicity. Therefore, it should be recognized that the interaction between an individual cell product and the lymphodepleting regimen may be a determinant of toxicities.

The incidence of ICANS seems to be highest for CD19-targeting CAR $\mathrm{T}$ cell therapies, potentially due to the robust $\mathrm{T}$ cell expansion seen with CD19 CAR T cell products. ${ }^{7} 19222731354851525679$ Neurological toxicity has been reported in studies of CAR $\mathrm{T}$ cells directed against CD22 and BCMA, but initial data suggest that ICANS may occur at lower rates than for CD19 CAR T cells, although the number of published studies is too small to make any definitive conclusions. ${ }^{16}{ }^{116}$ No studies have directly assessed differences in risk for ICANS between CAR $\mathrm{T}$ cells with CD28 and 4-1BB costimulatory motifs, and comparisons are complicated by the fact that these products were evaluated in trials with different grading systems, patient populations, and disease states. In general, neurological events were reported more frequently for axicabtagene ciloleucel $^{1}$ than tisagenlecleucel ${ }^{2}$ and the robust early expansion of CD28-costimulated CD19 CAR T cells could potentially set the stage for CRS and ICANS, but neurotoxicity has been reported in trials of products containing both costimulatory domains.

\section{Panel recommendations}

- Patients with high disease burden prior to infusion or treated with CD28-containing CAR T cell products may be at increased risk for developing neurotoxicity after CAR T cell therapy (LE: $3^{60117}$ ).

- Patients with grade 3-4 CRS are at higher risk of ICANS (LE: $4^{118}$ ).

- Product-specific and patient-specific risk assessments should guide treatment decisions for ICANS.

- Patients with evidence of recent or active intracranial hemorrhage should not undergo CAR T cell therapy (LE: $\left.4^{119}\right)$.

\section{Clinical signs and symptoms for identification of ICANS}

Common clinical manifestations of ICANS include confusion or delirium, expressive aphasia, weakness, tremor, headache, seizures, and altered level of consciousness. ${ }^{95}$ Headache alone is not considered a useful diagnostic symptom for ICANS, as it is very common with CRS and frequently co-occurs with fever. ${ }^{75}$ Seizures have occurred with variable frequency, with some centers observing nonconvulsive status epilepticus in roughly $10 \%$ of patients treated with CAR T and one study reporting generalized tonic-clonic seizures in roughly $30 \%$ of patients. ${ }^{45156}$

Aphasia, in particular anomia, and word-finding defects may be an important early warning sign, as one study of 53 patients with RR ALL found that $85 \%$ of subjects who displayed impaired naming of objects, stuttering, or perseverative speech after treatment with an anti-CD19
CAR T went on to develop severe ICANS. ${ }^{51}$ Handwriting changes have also been reported as the first sign to appear prior to the onset of high-grade ICANS. ${ }^{23} 28116$ Although CRS and ICANS are considered separate pathologies, fever precedes the onset of neurological symptoms in a majority of patients. ${ }^{23} 245156$

Cerebral edema may appear as areas of low density on unenhanced CT images and as increased T2 and FLAIR signal changes on MRI. Visible edema on neuroimaging is classified as grade 3 or grade 4 ICANS by the ASTCT consensus system, depending on whether it is local or diffuse. ${ }^{75}$ In the majority of cases, however, patients with ICANS frequently present with unremarkable MRI and CT scans. ${ }^{5179}$ Findings on EEG may reveal non-convulsive status epilepticus in CAR T-treated patients, with diffuse slowing and frontal intermittent rhythmic delta activity (FIRDA). ${ }^{48}$ However, FIRDA and generalized background slowing on EEG are both non-specific signs of diffuse cerebral dysfunction also seen in metabolic encephalopathy, infections, centrally acting medications, or neurodegeneration. ${ }^{120}$

\section{Panel recommendations}

- As per the ASTCT consensus grading system, mental status changes define the onset of ICANS after CAR T cell therapy.

- Brain CT or MRI may be used to evaluate cerebral edema in cases of grade 3 ICANS in adults, but the initiation of ICANS management should not be delayed for confirmation of neurological symptoms with imaging findings (LE: $4^{51}$ ).

\section{Timing of ICANS}

Across trials, the median time-to-onset of neurological events has been reported as $4-5$ days after infusion and resolution has typically been seen within 3-8 weeks. ${ }^{232456121}$ Neurological toxicity may occur earlier in patients treated with CD28 costimulated CAR $\mathrm{T}$ cells than for those receiving products with a $4-1 \mathrm{BB}$ domain. For axicabtagene ciloleucel, the median time to onset is 4 days after infusion, and for tisagenlecleucel, the median time to first event is 6 days. ${ }^{12}$ ICANS has been observed concurrently with CRS, shortly after CRS symptoms subside, as well as a delayed-onset form occurring up to 1 month after CAR T cell infusion. ${ }^{928114}$ The duration of neurological toxicities may vary depending on the product and disease state. For axicabtagene ciloleucel, the median duration was 17 days, and for tisagenlecleucel, the median duration was 6 days for patients with RR ALL and 14 days for patients with RR DLBCL. In most patients ICANS resolved within 3 weeks, although prolonged encephalopathy lasting up to 173 days was noted. ${ }^{12}$ Long-term follow-up studies of patients treated with CAR T cells are ongoing, and lateonset neurological events have been reported. Among 86 patients treated with CD19 CAR T cells in a phase I/II trial, $9(10 \%)$ were found to have 11 new neurological findings at a median of 28.1 months (range 12.1-62.6) after infusion, including three cerebrovascular accident 
events and one transient ischemic attack. Additionally, eight patients (9\%) experienced psychiatric events requiring intervention: four with newly diagnosed mood disorders and four with exacerbation of previous depression and anxiety. ${ }^{122}$

\section{Panel recommendations}

- Product label and product-specific REMS, or trial specific guidelines, should inform the duration and frequency of monitoring for ICANS after infusion.

- In patients deemed to be at high risk for developing ICANS, inpatient treatment, earlier imaging, or more frequent monitoring may be warranted.

- Patients treated with axicabtagene ciloleucel should be assessed for ICANS twice daily during the first week after infusion. The package insert requires at least once daily, but many experts recommend formal assessments more frequently (LE: $3^{2}$ ).

- As centers gain more experience administering CAR $\mathrm{T}$ cell therapies, requirements for monitoring may be modified with the best judgment of the treating physician.

\section{Management of ICANS}

Across several trials, tocilizumab has failed to resolve symptoms of ICANS, despite alleviating severe CRS. ${ }^{23} 245156$ It remains to be determined whether targeting IL-6R in isolation during established CRS is insufficient to prevent subsequent neurotoxicity or if the lack of efficacy is due to tocilizumab's inability to cross the blood-brain barrier. ${ }^{123}$ Because tocilizumab may not penetrate the CNS and causes at least a transient rise in serum IL-6, some have postulated that it may worsen neurotoxicity by increasing CSF IL-6 levels. ${ }^{56} 123$ Siltuximab, an anti-IL-6 antibody that may prevent high IL- 6 concentration in the CSF by removing it from circulation in the serum, and the IL-1 antagonist, anakinra, have both been proposed as potential alternatives, but data are lacking on their safety and efficacy.

Corticosteroids have been successfully used for the management of ICANS. The axicabtagene ciloleucel package insert advises $10 \mathrm{mg}$ IV dexamethasone every 6 hours for neurological toxicity of $\leq$ grade 3 and $1000 \mathrm{mg}$ IV methylprednisone daily for 3 days with grade 4 ICANS. ${ }^{1}$ Although corticosteroids may reduce circulating CAR $T$ cell counts, evidence is emerging that even longer courses of steroids ( $>7$ days) do not alter efficacy of cancer treatment. ${ }^{118}$ However, a trend towards shorter PFS has been observed in patients with lymphoma treated with axicabtagene ciloleucel who received longer and earlier intervention with steroids. ${ }^{102}$

Seizure prophylaxis has been implemented in a few studies, but the ideal dose and duration have not yet been determined. ${ }^{284851}$ Levetiracetam has a better drugdrug interaction profile and lower risk of cardiotoxicity compared with other antiepileptic agents, can be administered safely to patients with hepatic dysfunction, and does not affect cytokine levels. ${ }^{28}$ In the Memorial Sloan
Kettering Cancer Center trial, 14 patients developed seizure despite levetiracetam prophylaxis, but all resolved with standard management with benzodiazepines and antiepileptic agents. ${ }^{51}$

\section{Panel recommendations}

- Based on the expected neurotoxicities seen with different CAR T cell therapies, the management of ICANS should be risk-adjusted based on productspecific and patient-specific characteristics.

- Patients with CNS involvement of their disease may need earlier intervention for ICANS.

- Patients with history of inflammatory neurological conditions or current CNS disease involvement should be referred for additional neurological consultation prior to initiating CAR T cell therapy.

- For brain imaging in patients deemed high risk, MRI is preferred. If a patient is too unstable to transport, or fast-brain MRI is unavailable for pediatric patients (thus necessitating sedation), CT imaging may be used (LE: $4^{79}$ ).

- Because of the possibility that tocilizumab may worsen neurotoxicity, the management of neurotoxicity may take precedence over the management of low-grade CRS (LE: $5^{56123}$ ).

- For example, in the case of a patient with concomitant grade 1 CRS (fever) and grade 2 ICANS, steroids should be given.

- This does not apply to higher-grade CRS.

- If steroids are used in the management of ICANS, at least 2 doses should be given and a fast taper should be used once there is improvement (LE: $3^{12}$ ).

- For patients with grade 2 ICANS after being treated with 4-1BB CAR T cell products, such as tisagenlecleucel, steroids may be considered. Steroids are recommended for grade 3 or grade 4 ICANS (LE: $\left.4^{23117124}\right)$.

- For patients with grade 2 ICANS after being treated with CD28 costimulated CAR T cell products such as axicabtagene ciloleucel and brexucabtagen autoleucel, steroids should be used to mitigate the duration and severity of ICANS (LE: $3^{24125}$ ).

- To manage seizures in patients treated with CAR T cell therapies, levetiracetam is recommended (LE: $4^{2430}$ ).

- There is insufficient evidence to recommend prophylactic antiseizure medications to all patients undergoing CAR $\mathrm{T}$ cell therapies. However, in patients deemed to be at high-risk of developing neurotoxicity based on history, disease characteristics, or the product being administered, prophylactic levetiracetam may be considered (LE: $4^{51}$ ).

\section{Cerebral edema}

The high-profile termination of the phase II ROCKET trial (NCT02535364) of the investigational CD19-CAR T JCAR015 in adults with RR ALL raised concerns about the danger of fatal cerebral edema in patients undergoing IEC therapies. ${ }^{115}$ Fatalities were also reported during 
the safety expansion phase of the ZUMA- 1 study, ${ }^{36}$ in the standard of care setting, ${ }^{110}$ as well as the phase I/II trial of JCAR014, a defined composition $\mathrm{CD}^{+} / \mathrm{CD}^{+} \mathrm{CART}$ cell product for the treatment of RR ALL, CLL and NHL (NCT01865617). ${ }^{11}$ Initially, the use of fludarabine as a lymphodepleting agent was suspected as the etiological agent for cerebral edema, leading to a modified conditioning regimen in the ROCKET trial. However, subsequent fatalities, in addition to the distinct manifestation and timing of symptoms for adoptive $\mathrm{T}$ cell transferassociated neurotoxicity, led to the conclusion that fludarabine may not be the primary cause for cerebral edema and that the agent may continue to be safely used for lymphodepletion. ${ }^{97}$

All five patients who died in the ROCKET trial experienced rapid, early expansion of the modified CAR-bearing $\mathrm{T}$ cells within a week of being infused. Additionally, high levels of $\mathrm{CD}^{+} \mathrm{T}$ cells and a concurrent sharp spike in IL-2 and TNF- $\alpha$ were significantly correlated with fatal brain swelling. ${ }^{115}$ Postmortem analyses of patients from both the ROCKET and ZUMA studies revealed bloodbrain barrier disruptions in patients who succumbed to cerebral edema subsequent to CAR T treatment. ${ }^{56119} \mathrm{In}$ the ZUMA-2 trial, one case of grade 4 cerebral edema occurred; the patient had a full recovery and was in complete remission at 24 months of follow-up with no unresolved neurological sequela. ${ }^{14}$ Blood-brain barrier pathology was also reported in a patient who developed edema as a feature of CRS after CD19-directed CAR T therapy. ${ }^{126}$ Disruption of the blood-brain barrier may allow systemic cytokines including IFN- $\gamma$ to leak into the CSF, thus inducing vascular pericyte stress and the secretion of endothelial cell-activating cytokines. Therefore, there is speculation that patients with evidence of endothelial cell activation before lymphodepletion may be at increased risk of ICANS. ${ }^{56} \mathrm{~A}$ report has also surfaced of severe neurotoxicity consistent with posterior reversible encephalopathy syndrome in a phase I trial of CART-BCMA for multiple myeloma (NCT02546167), which resolved after high-dose methylprednisolone and cyclophosphamide. ${ }^{111}$

\section{Panel recommendation}

- If cerebral edema is suspected based on clinical signs and symptoms, patients should be immediately referred to intensive care where rapid imaging and management of intracranial hypertension should be performed (LE: $4^{119}$ ).

\section{CYTOPENIAS}

Lymphodepletion has become an important component of IEC therapies, associated with improved responses across trials, and regimens containing both fludarabine and cyclophosphamide are linked to better clinical outcomes. ${ }^{4} 2324363896127$ Hematological recovery after lymphodepletion and CAR $\mathrm{T}$ cell infusion varies across CAR T cell products, however, and hematological recovery for CD19-directed CAR T cell therapies may be more delayed. Grade 3 or 4 cytopenias persisting more than 30 days after CAR $\mathrm{T}$ cell infusion were observed in roughly $30 \%$ of patients receiving both axicabtagene ciloleucel and tisagenlecleucel. ${ }^{24} 3638$ Additionally, cytopenias were among the most common grade 3 or higher adverse events reported in the JULIET, ZUMA-1, ZUMA-2, and ELIANA trials. $^{14232438121}$ For newer products, such as BCMAtargeting bb2121, cytopenias were the most common events of grade 3 or higher, including neutropenia (in $85 \%$ of the patients), leukopenia (in $58 \%$ ), anemia (in $45 \%$ ), and thrombocytopenia (in $45 \%) .{ }^{16}$ Short-lived cytopenias are to be expected after the standard lymphodepletion regimen that is recommended with approved CAR T products, ${ }^{12}$ but prolonged cytopenias, even in the absence of lymphodepletion, may occur more frequently after CD19 CAR T cell therapy. ${ }^{5} 78$ Cytopenias may also be a hallmark of myelodysplastic syndromes, ${ }^{128}$ which is important to consider in the differential diagnosis. Risk factors for prolonged cytopenias observed in the ELIANA trial included prior HSCT, high disease burden, and highgrade CRS. Notably, no persistent cytopenias of grade 3 or higher were reported in trials of EGFRvIII- and HER2directed CAR $\mathrm{T}$ cell therapies for the treatment of glioblastoma. ${ }^{129130}$

\section{Timing of cytopenias}

In roughly one-third of patients treated with CD19directed CAR T cells, cytopenias persisting for $>1$ month have been reported. ${ }^{73} 5758$ One report has described prolonged cytopenias persisting for 15.2-21.7 months after CD19 CAR T cell treatment ${ }^{122}$ and another reported that $10 \%$ of adult lymphoma patients that remain in remission after axicabtagene ciloleucel may continue to experience grade 3-4 neutropenia 1 year after the therapy. ${ }^{131}$ Of note, the latter study of 85 patients in the standard of care setting noted that while $\mathrm{CD} 8^{+}$counts rapidly recovered, $\mathrm{CD} 4^{+} \mathrm{T}$ cells decreased from baseline and were persistently low with a median CD4 count of 155 cells $/ \mu \mathrm{L}$ for those remaining in remission 1 year after axicabtagene ciloluecel. ${ }^{131}$ For other therapies, hematological recovery following lymphodepletion generally occurs more rapidly. For example, $97 \%$ of patients receiving BCMA-targeting bb2121 CAR T cells who experienced grade 3 or higher cytopenias recovered to an absolute neutrophil count (ANC) of at least 1000 cells $/ \mu \mathrm{L}$ within 1 month. In that trial, the median time from infusion to recovery of an ANC of at least 1000 cells $/ \mu \mathrm{L}$ was 1.3 weeks (95\% CI 1.0 to 1.4 ) and recovery to a platelet count of at least $50,000 / \mu \mathrm{L}$ occurred in a median of 2.0 weeks (95\% CI 1.4 to 8.4). ${ }^{16} 132$

One study identified a biphasic pattern to cytopenias following CD19 CAR T cell therapy. In the trial, 27 of 29 responding patients experienced cytopenias later than 21 days postinfusion. Of the 22 patients who experienced late neutropenia, 15 showed two distinct nadirs in absolute neutrophil counts with one trough shortly after lymphodepletion and a second occurring more than 40 days after infusion. A similar biphasic pattern occurred 
in the 22 patients who experienced grade 3 thrombocytopenia, with 10 patients displaying an initial recovery of platelet counts before a second nadir between 20 and 40 days after infusion. ${ }^{133}$ In another analysis, baseline platelet counts of $<75,000$ and the early onset of CRS on day 0 or day +1 following infusion were associated with a higher likelihood of development of severe and prolonged cytopenias, which in some cases required therapy as for graft failure following allo-HSCT. ${ }^{132}$

\section{Panel recommendations}

- For cytopenias occurring within the first 28 days after IEC infusion, a bone marrow biopsy may not be indicated-complete blood counts with differential may be adequate for follow-up (LE: $4^{133} 134$ ).

- Clinically stable, afebrile pediatric patients may be discharged from the hospital before blood counts recover, though antimicrobial and antifungal prophylaxis should be considered.

- For cytopenias persisting $>28$ days after IEC infusion, bone marrow biopsy and bone marrow aspiration should be performed in addition to the standard work-up to assess response and cellularity, including assessment of viral pathogens (LE: $4^{133} 134$ ).

\section{Increased risk factors for cytopenias upon assessment}

A correlation between late (more than 21 days after infusion) thrombocytopenia, neutropenia and anemia was observed ( $\mathrm{p}=0.018$ for thrombocytopenia and neutropenia, $\mathrm{p}<0.0001$ for thrombocytopenia and anemia, and $\mathrm{p}=0.05$ for anemia and neutropenia) in a phase $\mathrm{Ib} / \mathrm{II}$ trial of CD19 CAR T cells for 38 children and adults with RR B cell cancers. In that study, prior HSCT $(\mathrm{p}=0.0015,0.0083$, and 0.02 for anemia, thrombocytopenia, and neutropenia) and higher CRS grade ( $\mathrm{p}=0.003,0.018$, and 0.04 for late anemia, thrombocytopenia, and neutropenia) predicted the development of cytopenias. ${ }^{133}$ Grade 3 or 4 CRS was also linked to delayed hematological recovery in 133 patients with RR B-ALL, CLL, or NHL who underwent lymphodepletion chemotherapy followed by infusion of CD19 CAR T cells. Examination of bone marrow biopsies from patients with grade 4 CRS showed no evidence of increased hemophagocytosis that might contribute to the delayed recovery; however, pretreatment bone marrow disease burden and a high number of prior therapies were associated with prolonged cytopenias in the study population. ${ }^{57}$

\section{Panel recommendations}

- Patients who develop high-grade CRS may be at increased risk for developing prolonged neutropenia (LE: $\left.4^{122}\right)$.

- Adults and children treated with CAR T cells outpatient should be hospitalized if they develop active infections or febrile neutropenia or per institutional guidelines. Evaluation for immune-mediated cytopenias could be considered, depending on the clinical circumstance.

\section{Management of cytopenias}

The package insert for tisagenlecleucel recommends against using myeloid growth factors, particularly GM-CSF during the first 3 weeks after cell infusion or until CRS has resolved because GM-CSF may theoretically aggravate CRS. ${ }^{16}$ Some centers recommend filgrastim (recombinant G-CSF) for all patients with ANCs lower than $500 / \mu \mathrm{L} .{ }^{28} 31$ Without growth factor support, thrombocytopenia and anemia may resolve more slowly than neutropenia. One retrospective analysis of $32 \mathrm{RR}$ DLBCL patients treated with CD19 CAR T cells observed median times to neutrophil, platelet, and hemoglobin recoveries of 11 days (range 5-218 days), 59.5 days (range 4-241 days), and 76 days (range 0-218 days), respectively. Fifteen patients in the cohort were treated with filgrastim. ${ }^{134}$

\section{Panel recommendations}

- For neutropenia during the first 28 days after CAR $\mathrm{T}$ cell infusion, G-CSF has been used. To avoid interaction with the peak CRS risk and CART expansion period, consider holding growth factors until day 14 from infusion of CAR T cells or once CRS has resolved (LE: $4^{133}$ ).

- For persistent neutropenia $(\mathrm{ANC}<500$ cells $/ \mu \mathrm{L})$ after day 28 following CAR $\mathrm{T}$ cell infusion, growth factors should be considered (LE: $4^{134}$ ).

- If growth factors are administered, GM-CSF is not recommended until the risk period for CRS is over (usually 2 weeks) (LE: $5^{83}$ ).

\section{CARDIOLOGY}

Cardiac toxicities are reported at rates of $29 \%-39 \%$ in patients receiving tisgenlecleucel, axicabtagene ciloleucel, and brexucabtagene autoleucel. ${ }^{1-3}$ However, the interpretation of these data is challenging because definitions of cardiotoxicity may vary. A common definition of cardiac toxicity includes symptoms of heart failure and/or a decline of left ventricular ejection fraction (LVEF): symptomatic fall in LVEF from $\geq 5$ to $<55 \%$ or an asymptomatic reduction of LVEF from $\geq 10$ to $<55 \%$. However, additional definitions include an increase in serum troponin, a greater decline in LVEF, and a $>15 \%$ reduction in global longitudinal strain. ${ }^{135}$ The CTCAE grades cardiotoxicity based on symptomology, imaging abnormalities, and biomarker measurements, including troponins. ${ }^{136}$

Common cardiovascular and cardiac toxicities reported with CAR T cell therapies have included hypotension, new heart failure, worsening of pre-existing heart failure, and new arrhythmias (atrial fibrillation/flutter are common). Other cardiac events that have been observed are the following: non-sustained ventricular tachycardia (VT), prolonged corrected QT interval (QTc) with and without QTc prolonging medications or electrolyte abnormalities, other wide and narrow complex tachycardias, pericarditis, and myocarditis. ${ }^{42}$ While cardiac toxicities have generally resolved there have been a small number of cases that have led to mortality. A retrospective analysis of 
98 children with RR ALL treated at a single center with 4-1BB-costimulated anti-CD19 CAR T cells observed hypotension requiring inotropic support in 24 patients with a mean onset 4.6 days after CAR T cell infusion (range 1-9), including six patients receiving milrinone. Worsened systolic function occurred in 10 patients. ${ }^{137}$ In a retrospective study of 137 adult patients treated with CAR $\mathrm{T}$ cells, cardiac injury (defined as an increase in serum troponin) was documented in at least $21 \%$ of patients and the cardiovascular event rate was $12 \% .{ }^{91}$ An elevated serum troponin was noted prior to the occurrence of a cardiac event after CAR T cell infusion and was exclusively noted in those with CRS. No trials have directly addressed cardiac risk factors in the context of CAR T cell therapy; however, an observational study aiming to prospectively define the rate of occurrence, natural history, and progression of cardiac dysfunction after CD19 CAR T cell therapy in adults and to identify the patients at high risk of developing cardiovascular events is ongoing at the time of publication (NCT04026737).

\section{Baseline evaluation for cardiotoxicity}

A baseline measurement of cardiac function is important. Echocardiography is the principal technique for evaluating cardiac toxicity in patients with cancer and threedimensional echocardiography-derived LVEF correlates excellently with MRI findings, while two-dimensional speckle tracking echocardiography-derived strain can detect changes in myocardial mechanics before changes in LVEF occur. ${ }^{138-140}$ Historically, equilibrium radionuclide angiography/MUGA has been a preferred method for serial assessment of LVEF in adult patients undergoing cardiotoxic chemotherapy due to high reproducibility, low interobserver and intraobserver variability, and extensive validation literature. Routine use of MUGA has markedly diminished in recent years because of the relative ease of use and low cost of echocardiogram. ${ }^{141}$ Additionally, MUGA exposes patients to radiation through the use of 99m-technetium labeled red blood cells, making echocardiogram the preferred modality for monitoring adult and pediatric patients. ${ }^{142}$

Several cardiac biomarkers have established utility in the detection of cardiac injury with cancer therapies and have also been validated for their prognostic value both in symptomatic and asymptomatic patients free of cancer. For example, the N-terminal pro-brain natriuretic peptide (NT-proBNP) investigation of dyspnea in the emergency department study of 600 patients who presented in the emergency department with dyspnea found that increased serum NT-proBNP was the strongest independent predictor of a final diagnosis of acute congestive heart failure (OR 44; 95\% CI 21.0 to 91.0, $\mathrm{p}<0.0001)$ and NT-proBNP testing alone was superior to clinical judgment alone $(p=0.006) .{ }^{143}$ Cardiac troponins are the gold standard biomarker for myocardial injury, and high-sensitivity assays allow for the improved detection of heart tissue damage even in the absence of overt signs and symptoms. ${ }^{144} 145$ However, an elevated troponin may occur independently of acute myocardial infarction, and myriad etiologies have been linked to troponin release, including pulmonary embolism, heart failure, myocarditis, end-stage renal disease, tachycardia, strenuous exercise, septic shock, and treatment with cardiotoxic chemotherapy such as doxorubicin and with immune checkpoint inhibitor therapy. ${ }^{140} 146-149$

\section{Panel recommendations}

- In adults, baseline cardiac testing prior to CAR T cell therapy should include TTE, a serum troponin, and NT-proBNP/BNP (LE: $4^{91}{ }^{137}$ ).

- In adults, troponin and LVEF should be monitored in patients who develop CRS of ASTCT grade 2 or higher (LE: $4^{91}$ ).

- In children, left ventricular shortening fraction should be monitored at baseline and in patients with ASTCT grade 4 CRS.

\section{Increased risk factors for cardiotoxicity upon assessment}

Many patients treated with CAR $T$ cells have undergone several prior lines of therapy, including chemotherapy with cardiotoxic agents. According to some estimates, $57 \%-70 \%$ of elderly lymphoma patients and $50 \%-60 \%$ of childhood cancer survivors are treated with an anthracycline-containing regimen. ${ }^{149}$ Anthracyclines, especially doxorubicin, can cause irreversible, dose-dependent cardiac injury, and the risk for future complications increases with cumulative doses. The onset of a decreased LVEF may occur while a patient is on treatment with anthracyclines or several years later. ${ }^{149-151}$ Serial serum troponin measurement in 78 patients with hematological malignancies undergoing 142 treatment cycles, including various anthracyclines, revealed delayed subclinical myocardial damage even after minor anthracycline exposure, with peak levels observed on median day +21.5 (range day +6 to day +35 ) after initiation of anthracycline therapy. Follow-up echocardiography in 28 patients showed a greater decrease in LVEF in troponinpositive patients compared with the troponin-negative group (10\% vs $2 \%$; $\mathrm{p}=0.017) .{ }^{124}$

Elevated troponins and BNP/NT-proBNP have been associated with increased all-cause mortality and have been shown to predict heart failure in patients with cancer undergoing chemotherapy. ${ }^{152} 153$ Increased troponin levels correlated with decreased LVEF in patients with acute myeloid leukemia (AML) undergoing induction chemotherapy with anthracycline-containing regimens. ${ }^{154}$ Among patients undergoing CAR T cell therapy, elevated serum troponins have been observed prior to cardiac events and post-CAR T cell infusion. ${ }^{53}$

In addition to prior therapies, the risk factors for cardiac toxicity with treatment are likely similar to those for the development of severe CRS, specifically, disease burden and peak CAR T cell expansion. ${ }^{27} 28137155156$ The pathophysiology responsible for cardiac toxicity in the context of CAR T cell therapy has not been extensively studied; however, the inflammatory cytokine profile seen 
with CRS, specifically elevated levels of IL-6, has also been implicated in causing myocardial dysfunction in cases of septic shock. ${ }^{157}$ One of the hallmarks of CRS is hypotension, ${ }^{28} 29318590155156$ which may lead to distributive shock, myocardial injury, and arrhythmias. Medications that increase bleeding risk could accelerate the onset of lifethreatening shock.

The underlying cardiovascular substrate, beyond cardiovascular function, is also likely a risk factor for the development of cardiac injury and cardiovascular events with CAR T. Specifically, many adult patients receiving CAR $T$ cells may be elderly and have underlying cardiovascular risk factors such as hypertension and diabetes mellitus and may have established cardiovascular diseases such as heart failure and coronary artery disease. There are limited data specific to CAR T, but in a single retrospective study of 137 subjects, the rates of these cardiovascular risks were higher in those that subsequently developed cardiac injury. ${ }^{91}$

Patients with high preinfusion disease burden are also at risk of developing TLS, ${ }^{78} 10$ which may cause cardiac complications secondary to the flood of metabolites and electrolytes, including uric acid released into circulation. ${ }^{92}$ In particular, elevated serum uric acid has been implicated as a risk factor for cardiovascular events, including acute myocardial infarction, angina, and heart failure. ${ }^{158-160}$

\section{Panel recommendations}

- Patients with an increased burden of cardiovascular risk factors, with a prior cardiac insult (ie, prior myocardial infarct and prior coronary revascularization), significant valvular disease, a low ejection fraction or a cardiomyopathy, a history of heart failure or significant cardiac, arrhythmias, and a history of cardiac toxicity from prior therapies should receive an additional cardiac evaluation prior to CAR $\mathrm{T}$ cell therapy. Patients with significant cardiac disease may not be candidates for CAR T cell therapy, depending on the balance between disease and treatmentassociated risks (LE: $4^{91137}$ ).

- Patients with pre-existing heart failure, arrhythmias, or other significant cardiac history may warrant consideration of inpatient CAR T cell therapy.

- Based on the expected toxicities seen with different CAR $T$ cell therapies and disease states, the management of cardiac adverse events should be risk-adjusted based on product-specific and patient-specific characteristics. Patients deemed to be at high cardiac risk at baseline might need earlier intervention with tocilizumab and/or steroids at the onset of CRS.

- The measurement of a serum troponin and LVEF should be considered in patients with any grade CRS when additional risk stratification is needed (LE: $\left.1^{153}\right)$.

\section{Management of cardiovascular adverse events}

Coagulopathies frequently occur in the context of CRS, and disseminated intravascular coagulation has been reported at rates of more than $2 \%$ for the approved CAR T cell products. ${ }^{161}$ Patients with cancer are at higher risk of thromboembolism, and clots are a leading cause of death in patients undergoing chemotherapy. ${ }^{162} 163$ The goal of anticoagulation therapy is generally to prevent clot formation at the lowest possible dose of anticoagulant medication, and management in patients with cancer may be challenging because some agents are long acting, interact with other drugs and have narrow therapeutic windows. In particular, warfarin (Coumadin) has a serum half-life of, on average, roughly 40 hours and the duration of effect is $2-5$ days. ${ }^{164} 165$ Current major guidelines from the European Society for Medical Oncology, the National Comprehensive Care Network and International Clinical Practice recommend low molecular weight heparin over warfarin for thrombosis prophylaxis in patients with cancer. ${ }^{166-169}$

The risk for bleeding complications in patients treated with anticoagulants is considerable. A meta-analysis of 33 studies involving 4374 patient-years of oral anticoagulant therapy found that the case-fatality rate of major bleeding was $13.4 \%$ (95\% CI $9.4 \%$ to $17.4 \%$ ), and the rate of intracranial bleeding was 1.15 per 100 patient-years $(95 \%$ CI 1.14 to 1.16 per 100 patient-years). ${ }^{170}$ Multiple studies have demonstrated that the presence of malignant disease significantly increases risk of major bleeding after anticoagulation therapy with warfarin. ${ }^{171} 172$ Antiplatelet blood thinners such as aspirin also increase bleeding risks. Additionally, aspirin, and other cyclooxygenase (COX) inhibitors, have been demonstrated to suppress T cell activation by inhibiting $\mathrm{T}$ cell receptor signaling to p38 Mitogenactivated protein (MAP) kinase, ${ }^{173} 174$ though no large controlled trials have assessed whether COX-inhibition negatively affects the efficacy of CAR T cell therapy.

\section{Panel recommendations}

- Evidence of cardiac toxicity, elevated troponin, decrease in LVEF or significant arrhythmias, should prompt consideration of earlier intervention with IL-6 blockade and/or steroids or escalation of current treatment.

- Malignant arrhythmias or evidence of severe LV dysfunction is an indication of severe end organ damage and requires escalation of intervention.

- The medications that may be continued during CAR $\mathrm{T}$ cell therapy include beta blockers, angiotensin II receptor blockers, calcium channel blockers, and ACE inhibitors. If feasible, these medications should be changed from long-acting to short-acting formulations.

- The medications that should be discontinued prior to CAR $T$ cell therapy include antiplatelet agents such as aspirin and clopidogrel. In patients who recently underwent a coronary revascularization, management decisions regarding the cessation of antiplatelet agents should be made in conjunction with the primary cardiology team, and risk-benefit of proceeding with CAR T cell therapy should be considered. 
- Before proceeding with CAR T cell therapy, patients on therapeutic anticoagulants should be switched from long-acting to short-acting formulations, wherever possible. Long-acting anticoagulants can significantly potentiate bleeding risk during CRS.

- If platelet counts drop below $100,000 / \mu \mathrm{L}$ in patients undergoing CAR T cell therapy, dual-acting anticoagulants should be discontinued.

- If platelet counts drop below $50,000 / \mu \mathrm{L}$ in patients undergoing CAR $\mathrm{T}$ cell therapy, all anticoagulants should be discontinued unless a patient has a recent thrombosis.

- If platelet counts drop below $50,000 / \mu \mathrm{L}$ in patients undergoing CAR $\mathrm{T}$ cell therapy and the patient has a recent thrombosis, anticoagulants may be continued, but the dose should be reduced or platelet transfusions should be administered.

\section{ON-TARGET TOXICITIES: HYPOGAMMAGLOBULINEMIA}

The approved CAR $\mathrm{T}$ cell products, tisagenlecleucel, axicabtagene ciloleucel, and brexucabtagene autoleucel, all target CD19, which is expressed in normal and neoplastic $\mathrm{B}$ cells as well as follicular dendritic cells. ${ }^{175}$ Almost all patients who respond to CD19 CAR T cell therapy develop B cell aplasia after infusion. ${ }^{59155}$ In a phase I/IIa study of 75 children and young adults with RR B-ALL treated with tisagenleceucel, the rate of event-free survival at 6 months was $73 \%$ (95\% CI $60 \%$ to $82 \%$ ), and the probability of maintenance of B cell aplasia at 6 months after infusion was $83 \%$ (95\% CI $69 \%$ to $91 \%) .{ }^{23}$ All patients who responded to treatment in the ELIANA trial had B cell aplasia, and the probability of functional CAR $\mathrm{T}$ cell persistence and continued B cell aplasia at 6 months after infusion was $83 \% .{ }^{23}$ A study of humoral immunity in 16 adults and children who responded to tisagenlecleucel reported $\mathrm{B}$ cell aplasia persisting for a mean of 571 days following CAR T cell therapy ${ }^{54} \mathrm{CD} 19^{+} \mathrm{B}$ cells can recover, however. In the phase I study of CD19 CAR T cells with a CD28 costimulatory domain in children and young adults with RR leukemia in the pediatric oncology branch, B cells became detectable by 60 days in all responding patients. ${ }^{113}$ In the ZUMA-1 trial of adults with large B cell lymphomas treated with axicabtagene ciloleucel, $6(17 \%)$ of 35 assessable patients with ongoing responses had detectable B cells in their blood by 3 months after infusion; $20(61 \%)$ of 33 assessable patients had detectable B cells at 9 months; and 24 (75\%) of 32 assessable patients had detectable B cells at 24 months. ${ }^{36} \mathrm{In}$ ZUMA-2, grade 1 or 2 hypogammaglobulinemia occurred in $12(15 \%)$ subjects, and grade $\geq 3$ was observed in one subject. ${ }^{14}$ In 16 adults with DLBCL who achieved CR after being treated with tisagenlecleucel, polyclonal B cell recovery was sustained in $8(50 \%)$, and the median time to onset of sustained recovery was 6.7 months. ${ }^{121}$

\section{Increased risk factors for hypogammaglobulinemia upon assessment}

Hypogammaglobulinemia has been reported across trials, although the rates have varied, likely due to inconsistent definitions, follow-up times, patient ages and disease states. Further complicating matters, many patients who undergo CAR T cell therapy have undergone prior HSCT without revaccination and are thus beginning treatment with a limited antibody repertoire. Younger patients may be more susceptible to hypogammaglobulinemia, as total serum IgG levels gradually increase at early ages, with adult levels of $\mathrm{IgG}_{1}$ and $\mathrm{IgG}_{3}$ subtypes seen between ages 5 and 10 years and $\operatorname{IgG}_{0}$ not reaching maximum levels until adulthood, ${ }^{176}$ reflecting increasing plasma cell mass. The direct link between B cell depletion and hypogammaglobulinemia is difficult to establish because long-lived plasma cells are CD19 negative ${ }^{175177178}$ and therefore should not be direct targets for elimination by CD19 CAR T cells. Plasma cells persisting for at least 746 days in the absence of B cells has been reported in one patient treated with tisagenlecleucel, and the same study observed stable levels of pathogen-specific IgG despite prolonged B cell aplasia and decreasing total serum IgG in two adult patients. ${ }^{54}$

\section{Panel recommendation}

- Following CAR T cell therapy, B cell counts and serum immunoglobulins should be measured monthly (LE: $\left.4^{54}\right)$.

\section{Management of hypogammaglobulinemia}

Immunoglobulin replacement therapy is FDA-approved for the treatment of primary immunodeficiencies as well as select few secondary antibody deficiencies, including hypogammaglobulinemia in CLL. ${ }^{179} 180 \mathrm{~A}$ number of off-label uses of immunoglobulin supplementation have become incorporated into routine clinical practice, with varying levels of supporting evidence. Although longterm B cell aplasia and hypogammaglobulinemia can persist for several years after CAR T cell infusion, ${ }^{55181}$ no controlled studies have demonstrated definitive benefits for IgG supplementation. In trials where patients did receive IgG supplementation, no serious infections were reported after the initiation of replacement therapy. ${ }^{9} 1055$ One study of 28 patients with persistent B cell aplasia and agammaglobulinemia following CD19 CAR T cell therapy, where patients were transitioned from intravenous to subcutaneous immunoglobulin replacement at a median of 11.5 months (range 4-20), found that increasing serum IgG level was significantly associated with a lower rate of sinopulmonary infection $(\mathrm{p}=0.0072) .{ }^{182}$

All IgG preparations available in the USA are made from 10,000 to 50,000 units of plasma pooled from 3000 to 10,000 healthy blood donors. Donors are carefully screened for blood-borne pathogens, including HIV, hepatitis A, B, and C viruses, and parvovirus B19, and at least two distinct viral inactivation steps are used by all manufacturers. The adverse events associated with IgG infusions are typically transient, infusion-related reactions. Intravenous and subcutaneous formulations have been developed, and typical starting doses are in the range of $400-800 \mathrm{mg} / \mathrm{kg}$ every 3-4 weeks intravenously or $100-200 \mathrm{mg} / \mathrm{kg} /$ week subcutaneously. ${ }^{183}$ The decision 
to administer immunoglobulin replacement therapy may be constrained by product availability, as an ongoing national shortage has limited supplies at most centers at the time of writing this article. ${ }^{184}$

\section{Panel recommendations}

- For adult patients deemed to be at high risk of infections or with recurrent infections and for children with serum IgG levels less than $400 \mathrm{mg} / \mathrm{dL}$, immunoglobulin supplementation should be considered (LE: $\left.4^{183}\right)$.

- For patients with long-term B cell aplasia ( $>6$ months) already on IgG replacement, subcutaneous IgG supplementation can be given at home and may be considered (LE: $4^{182}$ ).

\section{OTHER TOXICITIES \\ Primary CAR induction-associated toxicities}

Additional toxicities associated with primary IEC induction have been described, including allergic reaction, sepsis, and TLS. One patient developed anaphylaxis and cardiac arrest within minutes of completing a third infusion of $\mathrm{T}$ cells that had been transduced with a CAR derived from a murine antibody to human mesothelin, ${ }^{185}$ although this appears to be an isolated incident.

More commonly, several studies have reported TLS after CAR $\mathrm{T}$ cell treatment, a pathology arising due to dramatic electrolyte and metabolite imbalances after widespread release of cancer cell contents into the bloodstream, which can cause kidney damage due to elevated levels of serum uric acid and LDH. ${ }^{92}$ To prevent TLS in patients from undergoing CAR $\mathrm{T}$ therapy, prophylactic allopurinol is sometimes administered prior to infusions. ${ }^{86}{ }^{186}$ However, several trials have reported TLS, despite preinfusion allopurinol. Symptoms typically resolved after fluid resuscitation and administration of the recombinant urate oxidase drug rasburicase. ${ }^{7810} 186$ In an analysis of 328 pediatric ALL patients undergoing chemotherapy, factors predictive of TLS were male sex (OR 1.8; $\mathrm{p}=0.041)$, age $\geq 10$ years $(\mathrm{OR} 4.5 ; \mathrm{p}<0.0001$ ), splenomegaly (OR 3.3; $\mathrm{p}<0.0001$ ), mediastinal mass (OR 12.2; $\mathrm{p}<0.0001$ ), T cell immunophenotype (OR 8.2; $\mathrm{p}<0.0001$ ), CNS involvement (OR 2.8; $\mathrm{p}=0.026$ ), serum $\mathrm{LDH} \geq 2000 \mathrm{U} / \mathrm{L}$ (OR 7.6; $<<0.0001$ ), and elevated white blood cell (WBC) counts $\left(\geq 20 \times 10^{9} / \mathrm{L}\right)$ (OR 4.7 ; $\mathrm{p}<0.0001) .{ }^{117}$ In two separate studies of TLS in patients with AML, predictive risk factors were male sex, $\mathrm{LDH}$ levels above normal values, creatinine $>1.4 \mathrm{mg} / \mathrm{dL}$, uric acid $>7.5 \mathrm{mg} / \mathrm{dL}$, and WBC count $>25 \times 10^{9} / \mathrm{L} .{ }^{187} 188$

Fatal sepsis has been reported after CAR $\mathrm{T}$ cell therapy. A 69-year-old man with refractory CLL, despite negative blood cultures at the time of infusion, died of acute renal failure consistent with sepsis after administration of 19-28z CAR T cells and cyclophosphamide. ${ }^{189}$ An analysis of infection events in 19 patients during the first 30 days after CD19 CAR T cell therapy developed a prediction model based on three cytokines (IL-8,
IL-1 $\beta$, and IFN- $\gamma$ ) that could predict life-threatening infection with high sensitivity (training $100.0 \%$; validation $100.0 \%$ ) and specificity (training $97.6 \%$; validation $82.8 \%$ ). During the study, a characteristic pattern of 'double peaks' of IL-6, where serum levels of the cytokine spiked, dropped and then rose again, appeared in 9 of 11 patients with grade $4-5$ infections. ${ }^{190}$

\section{Panel recommendations}

- TLS risk should be assessed by monitoring disease burden, and serum potassium, phosphorus, calcium, uric acid, and creatinine (LE: $3^{187188}$ ).

- If patients have significant bone marrow involvement or large amount of extramedullary disease, increased TLS risk should be a concern (LE: $1^{92}$ ).

- For prophylaxis against TLS prior to CAR T cell therapy, allopurinol should be administered (LE: $\left.4^{86}\right)$.

- In patients with established TLS after CAR T cell therapy, rasburicase should be considered (LE: $4^{810}$ ). Testing for G6PD deficiency prior to administration of rasburicase can be considered in patients at high risk of TLS.

\section{PATIENT ENGAGEMENT AND QUALITY OF LIFE}

While CAR Tcell or other IEC therapies may offer significant and durable antitumor responses for many patients, the appropriateness of any intervention ultimately depends on patient-specific considerations. It is important to consider potential effects on patient satisfaction and quality of life for a planned course of treatment. Additionally, all members of a caregiving team, as well as patients themselves, must undergo sufficient education in order to rapidly respond to any toxicities that do occur.

Due to the relative infancy of the field, few large-scale quality of life assessments for IEC therapies have been performed. In the short term, quality of life generally increases if patients experience clinically meaningful responses to therapy. An analysis of self-reported outcomes from the ELIANA trial encompassing 39 patients older than 8 years of age found mean changes from baseline for the PedsQL total and EQ-5D visual analog scale of 13.9 and 13.7 at month 3 and 12.8 and 10.9 at month 6 , respectively, supporting clinically meaningful improvements. Additionally, the proportions of patients reporting problems with mobility, self-care, usual activities, anxiety/depression, or pain/ discomfort were notably decreased at months 3 and $6 .{ }^{191}$ The long-term effects of CAR T cell therapy on quality of life remain understudied. One study of self-reported outcomes among 40 patients who completed a questionnaire containing the Patient-Reported Outcomes Measurement Information System (PROMIS) Scale V.1.2 Global Health and the PROMIS-29 Profile V.2.1, as well as 30 additional questions at a median of 3 years after CAR $\mathrm{T}$ cell treatment revealed that nearly $50 \%$ of patients in the cohort experienced at least 
one clinically meaningful negative neuropsychiatric outcome, including anxiety, depression, and cognitive difficulty. ${ }^{192}$ In that study, there was a trend toward significance $(\mathrm{p}=0.08)$ for an association between acute neurotoxicity and long-term neuropsychiatric problems. Overall, however, no difference was observed in mean mental health scores for patients treated with CAR T cells and the general population.

Financial distress may cause substantial detrimental effects on quality of life for patients with cancer, ${ }^{193}$ and IEC therapies are among the most expensive interventions in the healthcare system. The cost of a onetime infusion of tisagenlecleucel for pediatric ALL is US $\$ 475,000$, while the cost of tisagenlecleucel for adult NHL, axicabtagene ciloleucel for adult NHL, and brexucabtagene autoleucel for MCL is US\$373,000. Patients may also incur additional expenses for transportation to and from the hospital and accommodations nearby during treatment. Despite these prices, CAR T cell therapies have been demonstrated to be cost-effective in terms of life-years and quality-adjusted life years (QALYs) gained. A study of CAR T cell therapy versus standard of care for pediatric patients with RR B-ALL found that tisagenlecleucel treatment led to 10.34 discounted life-years gained and 9.28 QALYs gained, amounting to an incremental cost-effectiveness ratio of approximately US $\$ 42,000$ per life-year gained and approximately US $\$ 46,000$ per QALY gained compared with clofarabine. ${ }^{194}$ An economic framework for therapy valuation found that CAR $\mathrm{T}$ cell therapy for patients with pediatric RR ALL and DLBCL generated as much as US $\$ 6.5$ billion and US $\$ 35.8$ billion in social value. ${ }^{195}$

\section{Panel recommendations}

- Prior to initiating therapy, patient education should include an in-person nursing 'teach' visit and a meeting with a social worker.

- Patient education prior to therapy should include the difference between approved products and clinical trials, lymphodepletion chemotherapy, timing of infusion visits, expected side effects, strategies to manage side effects, expectations for hospital admission, infection precautions, CRS, neurological events, financial considerations, screening studies, outpatient follow-up requirements, intravenous access on admission, timeline to produce cells, and potential need for interim therapy.

- Call parameters for patients undergoing outpatient CAR T cell therapy should include fever, chills, difficulty breathing, changes in mental status, difficulty with mobility, and vision changes.

- Prior to CAR T cell therapy, patients should be asked about family support.

- Prior to initiating therapy, patients should be asked about what type of financial/housing/transportation support they will require if they need to relocate for a period of time.
- Quality of life should be evaluated using validated tools such as the European Organization for Research and Treatment of Cancer Quality of Life Questionnaire-Core Questionnaire, the EuroQol-5 Dimension, PROMIS, or Patient-Reported Outcome Common Terminology Criteria for Adverse Events (PRO-CTCAE), depending on study protocols or institutional policies.

- For infection precautions during CAR T cell therapy, hand hygiene should be discussed with patients and caretakers. Seasonal influenza vaccination should also be encouraged for all household members.

\section{CONCLUSION}

Although the toxicities associated with IEC therapy may come on suddenly and progress rapidly, most adverse events are treatable when prompt diagnosis is made. A collaborative effort of different specialties including intensive care, neurology, cardiology, emergency medicine, and infectious disease, in addition to the cell therapy team, is critical for the successful management of toxicities. At this time, IEC therapies should be delivered with direct involvement by cell therapists at centers with transplant programs, accreditation by FACT or the Joint Accreditation Committee ISCTEurope (JACIE), and experienced ICUs. Future studies to add insight into the underlying pathogenesis and pathogenomic features of IEC-related toxicities have the potential to further improve outcomes for patients undergoing these potentially lifesaving therapies. As more and more patients are treated with approved and emerging immunotherapies, additional research will be necessary to understand how immune-modulating agents may potentially interact or synergize with cellbased treatments.

\section{Author affiliations}

${ }^{1}$ Department of Medicine, Massachusetts General Hospital Cancer Center, Boston, Massachusetts, USA

${ }^{2}$ Cancer Center, Massachusetts General Hospital, Boston, Massachusetts, USA ${ }^{3}$ Department of Medicine, The University of Chicago, Chicago, Illinois, USA

${ }^{4}$ Surgery Branch, National Cancer Institute, Bethesda, Maryland, USA

${ }^{5}$ Cancer Immunotherapy Program, Division of Oncology, Children's Hospital of Philadelphia, Philadelphia, Pennsylvania, USA

${ }^{6}$ Blood and Marrow Transplantation and Cellular Immunotherapy, Moffitt Cancer Center, Tampa, Florida, USA

${ }^{7}$ Cellular Therapeutics Center, Memorial Sloan Kettering Cancer Center, New York, New York, USA

${ }^{8}$ Department of Neurology, Massachusetts General Hospital, Boston, Massachusetts, USA

${ }^{9}$ Department of Anesthesiology and Critical Care, Children's Hospital of Philadelphia and University of Pennsylvania, Philadelphia, Pennsylvania, USA

${ }^{10}$ Bone Marrow Transplant and Cellular Immunotherapy Program, Massachusetts General Hospital, Boston, Massachusetts, USA

${ }^{11}$ Pediatric Hematology/Oncology/BMT, Children's Hospital Colorado and University of Colorado Anschutz School of Medicine, Aurora, Colorado, USA

${ }^{12}$ Department of Hematology/Oncology/Bone Marrow Transplant and Cellular Therapy, The University of Oklahoma Stephenson Cancer Center, Oklahoma City, Oklahoma, USA

${ }^{13}$ Sylvester Comprehensive Cancer Center, University of Miami, Miami, Florida, USA ${ }^{14}$ Department of Pediatrics, University of Virginia Cancer Center, Charlottesville, Virginia, USA 
${ }^{15}$ Department of Blood and Marrow Transplant and Cellular Immunotherapy, Moffitt Cancer Center, Tampa, Florida, USA

${ }^{16}$ Department of Pediatrics, University of Pennsylvania, Philadelphia, Pennsylvania, USA

${ }^{17}$ Department of Medicine, Roswell Park Comprehensive Cancer Center, Buffalo, New York, USA

${ }^{18}$ Department of Anesthesiology and Critical Care Medicine, Memorial Sloan Kettering Cancer Center, New York, New York, USA

${ }^{19}$ Department of Lymphoma and Myeloma, The University of Texas MD Anderson

Cancer Center, Houston, Texas, USA

${ }^{20}$ Division of Cardiology, Department of Medicine, Massachusetts General Hospital, Boston, Massachusetts, USA

${ }^{21}$ Department of Neurology, Memorial Sloan Kettering Cancer Center, New York, New York, USA

${ }^{22}$ Department of Stem Cell Transplantation and Cellular Therapy, The University of Texas MD Anderson Cancer Center, Houston, Texas, USA

${ }^{23}$ Cancer Center, Children's Hospital of Philadelphia and University of Pennsylvania, Philadelphia, Pennsylvania, USA

${ }^{24}$ Clinical Research Division, Fred Hutchinson Cancer Research Center Division of Medical Oncology, University of Washington, Seattle, Washington, USA

${ }^{25}$ Emily Whitehead Foundation, Phillipsburg, Pennsylvania, USA

${ }^{26}$ Cancer Immunotherapy Program, Division of Oncology, Children's Hospital of Philadelphia and University of Pennsylvania, Philadelphia, Pennsylvania, USA

Twitter Marco L Davila @marcoldavila, Matthew J Frigault @MJFzeta and Stephan A Grupp gruppsteve, and SITC @sitcancer

Acknowledgements The authors acknowledge SITC staff for their contributions, including Sam Million-Weaver, PhD, for medical writing and editorial support and Angela Kilbert; Ben Labbe, PhD, and Lionel Lim for project management and assistance. Additionally, the authors wish to thank the society for supporting the article development. SITC wishes to thank the American Society for Hematology (ASH), the American Society for Transplantation and Cellular Therapy (ASTCT), the Foundation for the Accreditation of Cellular Therapy (FACT) at the University of Nebraska Medical Center, and the Emily Whitehead Foundation for providing representatives to serve on SITC's Immune Effector Cell-related Adverse Events Expert Panel

Contributors All authors served on the SITC Immune Effector Cell-related Adverse Events Guideline Expert Panel, drafted content, and provided critical review during the article development. MVM and SAG provided leadership as Chairs of the Expert Panel and provided guidance on the article structure and content, and thus are first and last authors; all other authors contributed equally to the article development and review and therefore are listed alphabetically by last name. TW was the patient advocate representative. All authors have read and approved the final version of this article.

Funding The authors have not declared a specific grant for this research from any funding agency in the public, commercial or not-for-profit sectors.

Competing interests CC-Consultant and/or advisory board: Novartis. MLD-Consultant and/or advisory board: Celyad, Novartis; Research/license support: Atara, Celgene; Stock option: Adaptive Biotechnologies, Precision Bioscience. CD—Consultant and/or advisory board: Evidera, Juno. JD-Consultant and/or advisory board: Unum Therapeutics, Blue Earth Diagnostics; Royalties: Wolters Kluwer. JCF-NIDDK 23 grant. MJF-Consultant and/or advisory board: Arcelex, Celgene, Nkarta, Novartis, Xenetic Bio. JLH-C-At-large board member: ASTCT; Vice Chair: Government affairs, Task force member on Immunotherapies and Palliative Care, ASH; Co-Primary Investigator: Imaging trial haplo/cord, graft failure NHLBI R01 grant. SAG-Consultant and/or advisory board: Adaptimmune, Allogene, Cellectis, Eureka, GlaxoSmithKline, Humanigen, J\&J/Janssen, Juno, Novartis, Roche, TCR2, Vertex/CRISPR Therapeutics; Grant/research support: Kite Gilead, Novartis, Servier, Vertex. KVK-Consultant or SAB: Kite/Gilead, Autolus, Juno/ BMS, Celgene, Novartis, Takeda, Kiadis, Incyte, Atara, Legend, Kadmon, Helocyte; Clinical trials support (institutional): Kite/Gilead, Novartis, Atara, Allogene; Nonprofit organizations: National Marrow Donor Program (Board of Directors), ASTCT (Chair, cell therapy committee). DWL-Owner: Immchase, LLC; Consultant and/or advisory board: ACI Clinical (on behalf of Celgene), Harpoon Therapeutics, Juno Therapeutics. FLL-Scientific advisor: Kite/Gilead, Novartis, BMS/Celgene, Allogene, Wugen, Calibr, Gamma Delta Therapeutics; Consultant: Cellular Biomedicine Group Inc; Research support: Kite/Gilead. SLM-Consultant and/or advisory board: Kite, Novartis. MVM-Consultant and/or advisory board: Adaptimmune, Adaptive Biotechnologies, Argentus, BD Sciences, Bluebird Bio, Cell Signaling, Collectis (SAB), CRISPR
Therapeutics, EMD Serono, Inysus, Kite, Juno, MPM, Novartis, Takeda, TCR2 (SAB), Third Rock Ventures, WindMIL (SAB); Grant/research support: CRISPR Therapeutics, Kite Gilead. PLM-Consultant and/or advisory board: BlueBird Biotech, BMS, Celgene, Fate Therapeutics, Janssen, Juno, Karyopharm, Magenta Therapeutics, MedScape, Sanofi, Takeda. SSN-Consultant and/or advisory board: Celgene, Cell Medica, Incyte, Kite/Gilead, Merck, Novartis, Pfizer, Precision Biosciences, Unum Therapeutics; Grant/research support: Acerta, BMS, Collectis, Karus, Kite Gilead, Merck, Poseida, Unum Therapeutics. TGN-Consultant on imaging: Parexel, Intrinsic Imaging; SAB on Checkpoint and Myocarditis: BMS; Consultant: H3 Biomedicine, Aprea Therapeutics. BDS-Consultant and/or advisory board: Kite Gilead, Juno/ Celgene, Insysus, Novartis, Janssen; Grant/research support: ADC Therapeutics. EJS-Consultant and/or advisory board: Adaptimmune, Cellgene, Magenta, Novartis, Partner Therapeutics. DTT-Advisory board: La Roche, Amgen, Janssen, Novartis. CJT-Consultant and/or advisory board: Aptevo, Arsenal Bio, AstraZeneca, Caribou Biosciences, Century Therapeutics, Eureka Therapeutics, Humanigen, Juno/ BMS, Kite/Gilead, Myeloid Therapeutics, Nektar Therapeutics, Novartis, Precision Biosciences, T-CURX; Stock options: Precision Biosciences, Eureka Therapeutics, Caribou Biosciences, Arsenal Bio, Myeloid Therapeutics; Grant/research support: Juno/BMS, Nektar Therapeutics, AstraZeneca. SA, MRB, JNB, TJF, EM, and TW-Nothing to disclose. SITC staff: AK, BL, LL and SMW-Nothing to disclose.

Patient consent for publication Not required.

Provenance and peer review Not commissioned; externally peer reviewed.

Open access This is an open access article distributed in accordance with the Creative Commons Attribution Non Commercial (CC BY-NC 4.0) license, which permits others to distribute, remix, adapt, build upon this work non-commercially, and license their derivative works on different terms, provided the original work is properly cited, appropriate credit is given, any changes made indicated, and the use is non-commercial. See http://creativecommons.org/licenses/by-nc/4.0/.

\section{ORCID iDs}

Marcela V Maus http://orcid.org/0000-0002-7578-0393

Michael R Bishop http://orcid.org//0000-0002-3979-9273

Jennifer N Brudno http://orcid.org/0000-0002-7904-8415

Marco L Davila http://orcid.org/0000-0002-6270-3065

Matthew J Frigault http://orcid.org/0000-0002-6774-5694

Jennifer L Holter-Chakrabarty http://orcid.org/0000-0003-1425-7002

Frederick L Locke http://orcid.org/0000-0001-9063-6691

Philip L McCarthy http://orcid.org/0000-0002-9577-3879

Tomas G Neilan http://orcid.org/0000-0002-1513-8833

David T Teachey http://orcid.org/0000-0001-7373-8987

Cameron J Turtle http://orcid.org/0000-0002-4722-4461

Stephan A Grupp http://orcid.org/0000-0001-8030-7595

\section{REFERENCES}

1 Kite. Yescarta package insert, 2017. United States FDA. Available: https://www.fda.gov/media/108377/download

2 Novartis. Kymriah package insert, 2017. United States FDA. Available: https://www.fda.gov/media/107296/download

3 Kite. Tecartus package insert, 2020. United States FDA. Available: https://www.fda.gov/media/140409/download

4 Brentjens RJ, Davila ML, Riviere I, et al. CD19-Targeted T cells rapidly induce molecular remissions in adults with ChemotherapyRefractory acute lymphoblastic leukemia. Sci Trans/ Med 2013:5:177ra38-177.

5 Brudno JN, Somerville RPT, Shi V, et al. Allogeneic T cells that express an anti-CD19 chimeric antigen receptor induce remissions of B-cell malignancies that progress after allogeneic hematopoietic stem-cell transplantation without causing graft-versus-host disease. J Clin Oncol 2016;34:1112-21.

6 Freyer CW. Tisagenlecleucel: the first CAR on the highway to remission for acute lymphoblastic leukemia. J Adv Pract Oncol 2018;9:537-44 https://www.ncbi.nlm.nih.gov/pmc/articles/ PMC6505546/

7 Grupp SA, Kalos M, Barrett D, et al. Chimeric antigen receptormodified T cells for acute lymphoid leukemia. N Engl J Med Overseas Ed 2013;368:1509-18

8 Kochenderfer JN, Dudley ME, Carpenter RO, et al. Donor-Derived CD19-targeted $T$ cells cause regression of malignancy persisting after allogeneic hematopoietic stem cell transplantation. Blood 2013;122:4129-39.

9 Maude SL, Frey N, Shaw PA, et al. Chimeric antigen receptor T cells for sustained remissions in leukemia. $N$ Engl J Med 2014;371:1507-17. 
10 Porter DL, Levine BL, Kalos M, et al. Chimeric antigen receptormodified T cells in chronic lymphoid leukemia. N Engl J Med 2011;365:725-33

11 Turtle CJ, Hay KA, Hanafi L-A, et al. Durable molecular remissions in chronic lymphocytic leukemia treated with CD19-specific chimeric antigen receptor-modified T cells after failure of ibrutinib. $\mathrm{J}$ Clin Oncol 2017;35:3010-20.

12 Garfall AL, Maus MV, Lacey SF, et al. Safety and efficacy of antiCD19 chimeric antigen receptor (CAR)-modified autologous T cells (CTL019) in advanced multiple myeloma. JCO 2015;33:8517

13 Porter DL, Frey NV, Loren AW, et al. A phase II, dose-optimization trial of autologous $T$ cells genetically engineered to express antiCD19 chimeric antigen receptor (CART-19) in patients with relapsed or refractory (r/r) CD19+ chronic lymphocytic leukemia (CLL). JCO 2013;31:TPS7132

14 Wang M, Munoz J, Goy A, et al. KTE-X19 CAR T-cell therapy in relapsed or refractory mantle-cell lymphoma. $N$ Engl J Med 2020;382:1331-42.

15 Berdeja JGet al. Durable clinical responses in heavily pretreated patients with relapsed/refractory multiple myeloma: updated results from a multicenter study of bb2121 Anti-Bcma CAR T cell therapy. Blood 2017;130:740.

16 Raje N, Berdeja J, Lin Y, et al. Anti-BCMA CAR T-cell therapy bb2121 in relapsed or refractory multiple myeloma. N Engl J Med Overseas Ed 2019;380:1726-37.

17 Zhao W-H, Liu J, Wang B-Y, et al. A phase 1, open-label study of LCAR-B38M, a chimeric antigen receptor $T$ cell therapy directed against $\mathrm{B}$ cell maturation antigen, in patients with relapsed or refractory multiple myeloma. J Hematol Oncol 2018;11:141.

18 Alonso-Camino V, Harwood SL, Álvarez-Méndez A, et al. Efficacy and toxicity management of CAR-T-cell immunotherapy: a matter of responsiveness control or tumour-specificity? Biochem Soc Trans 2016:44:406-11.

19 Anderson K, Latchford T. Associated toxicities: assessment and management related to CAR T-cell therapy. Clin J Oncol Nurs 2019;23:13-19.

20 Fishman JA, Hogan JI, Maus MV. Inflammatory and infectious syndromes associated with cancer immunotherapies. Clin Infect Dis 2019;69:909-20.

21 Frey N, Porter D. Cytokine release syndrome with chimeric antigen receptor T cell therapy. Biol Blood Marrow Transplant 2019;25:e123-7.

22 Gofshteyn JS, Shaw PA, Teachey DT, et al. Neurotoxicity after CTL019 in a pediatric and young adult cohort. Ann Neurol 2018;84:537-46.

23 Maude SL, Laetsch TW, Buechner J, et al. Tisagenlecleucel in children and young adults with B-cell lymphoblastic leukemia. $N$ Engl J Med 2018;378:439-48.

24 Neelapu SS, Locke FL, Bartlett NL, et al. Axicabtagene Ciloleucel CAR T-cell therapy in refractory large B-cell lymphoma. N Engl J Med 2017;377:2531-44.

25 Graham R, Mancher M. Clinical practice guidelines we can trust. Washington DC: National Academies Press, 2011.

26 Howick J, Chalmers I, Glasziou P, et al. Explanation of the 2011 Oxford centre for evidence-based medicine (OCEBM) levels of evidence (background document), 20110xford Centre for EvidenceBased Medicine. Available: https://www.cebm.ox.ac.uk/resources/ levels-of-evidence/explanation-of-the-2011-ocebm-levels-ofevidence/

27 Titov A, Petukhov A, Staliarova A, et al. The biological basis and clinical symptoms of CAR-T therapy-associated toxicites. Cell Death Dis 2018:9:897.

28 Neelapu SS, Tummala S, Kebriaei P, et al. Chimeric antigen receptor T-cell therapy - assessment and management of toxicities. Nat Rev Clin Oncol 2018;15:47-62.

29 Neelapu SS. Managing the toxicities of car T-cell therapy. Hematol Oncol 2019;37 Suppl 1:48-52.

30 Dholaria BR, Bachmeier CA, Locke F. Mechanisms and management of chimeric antigen receptor T-cell therapy-related toxicities. BioDrugs 2019;33:45-60.

31 Brudno JN, Kochenderfer JN. Toxicities of chimeric antigen receptor T cells: recognition and management. Blood 2016;127:3321-30.

32 Teachey DT, Bishop MR, Maloney DG, et al. Toxicity management after chimeric antigen receptor T cell therapy: one size does not fit 'ALL'. Nat Rev Clin Oncol 2018;15:218.

33 van der Stegen SJC, Hamieh M, Sadelain M. The pharmacology of second-generation chimeric antigen receptors. Nat Rev Drug Discov 2015:14:499-509.

34 Salter AI, Ivey RG, Kennedy JJ, et al. Phosphoproteomic analysis of chimeric antigen receptor signaling reveals kinetic and quantitative differences that affect cell function. Sci Signal
2018;11. doi:10.1126/scisignal.aat6753. [Epub ahead of print: 21 Aug 2018].

35 Hirayama AV, Turtle CJ. Toxicities of CD19 CAR-T cell immunotherapy. Am J Hematol 2019;94:S42-9.

36 Locke FL, Ghobadi A, Jacobson CA, et al. Long-Term safety and activity of axicabtagene ciloleucel in refractory large B-cell lymphoma (ZUMA-1): a single-arm, multicentre, phase 1-2 trial. Lancet Oncol 2019;20:31-42.

37 Kochenderfer JN, Dudley ME, Kassim SH, et al. Chemotherapyrefractory diffuse large B-cell lymphoma and indolent B-cell malignancies can be effectively treated with autologous $T$ cells expressing an anti-CD19 chimeric antigen receptor. J Clin Oncol 2015;33:540-9.

38 Schuster SJ, Bishop MR, Tam CS, et al. Tisagenlecleucel in adult relapsed or refractory diffuse large B-cell lymphoma. N Engl J Med 2019;380:45-56.

39 Abramson JS, Palomba ML, Arnason JE, et al. Lisocabtagene maraleucel (liso-cel) treatment of patients (PTS) with relapsed/ refractory $(\mathrm{R} / \mathrm{R}) \mathrm{B}$-cell non-Hodgkin lymphoma $(\mathrm{NHL})$ and secondary CNS lymphoma: initial results from TRANSCEND NHL 001. Journal of Clinical Oncology 2019;37:7515

40 Abramson JS, Palomba ML, Gordon LI, et al. Pivotal safety and efficacy results from Transcend NHL 001, a multicenter phase 1 study of Lisocabtagene Maraleucel (liso-cel) in relapsed/refractory (R/R) large B cell lymphomas. Blood 2019;134:241

41 Verma D, Kantarjian H, Faderl S, et al. Late relapses in acute myeloid leukemia: analysis of characteristics and outcome. Leuk Lymphoma 2010;51:778-82.

42 Forman SJ, Rowe JM. The myth of the second remission of acute leukemia in the adult. Blood 2013;121:1077-82.

43 Gaudio F, Giordano A, Pavone V, et al. Outcome of very late relapse in patients with Hodgkin's lymphomas. Adv Hematol 2011;2011:707542.

44 Bishop MR, Maziarz RT, Waller EK, et al. Tisagenlecleucel in relapsed/refractory diffuse large B-cell lymphoma patients without measurable disease at infusion. Blood Adv 2019;3:2230-6.

45 Bitterman R, Eliakim-Raz N, Vinograd I, et al. Influenza vaccines in immunosuppressed adults with cancer. Cochrane Database Syst Rev 2018;2:CD008983-8983.

46 Traube C, Silver G, Kearney J, et al. Cornell assessment of pediatric delirium: a valid, rapid, observational tool for screening delirium in the PICU*. Crit Care Med 2014;42:656-63.

47 Mahadeo KM, Khazal SJ, Abdel-Azim H, et al. Management guidelines for paediatric patients receiving chimeric antigen receptor T cell therapy. Nat Rev Clin Oncol 2019;16:45-63.

48 Rice J, Nagle S, Randall J, et al. Chimeric antigen receptor cell-related neurotoxicity: mechanisms, clinical presentation, and approach to treatment. Curr Treat Options Neurol 2019;21:40.

49 Wang Z, Han W. Biomarkers of cytokine release syndrome and neurotoxicity related to CAR-T cell therapy. Biomark Res 2018;6:4.

50 Teachey DT, Lacey SF, Shaw PA, et al. Identification of predictive biomarkers for cytokine release syndrome after chimeric antigen receptor T-cell therapy for acute lymphoblastic leukemia. Cancer Discov 2016;6:664-79.

51 Santomasso BD, Park JH, Salloum D, et al. Clinical and biologica correlates of neurotoxicity associated with CAR T-cell therapy in patients with B-cell acute lymphoblastic leukemia. Cancer Discov 2018;8:958-71.

52 Hay KA. Cytokine release syndrome and neurotoxicity after CD19 chimeric antigen receptor-modified (CAR-) T cell therapy. Br J Haematol 2018;183:364-74.

53 Alvi RM, Mahmood S, Hassan MZO, et al. The cardiovascular effects of chimeric antigen receptor T-cells. J Am Coll Cardiol 2019;73:722.

54 Bhoj VG, Arhontoulis D, Wertheim G, et al. Persistence of long-lived plasma cells and humoral immunity in individuals responding to CD19-directed CAR T-cell therapy. Blood 2016;128:360-70.

55 Kochenderfer JN, Wilson WH, Janik JE, et al. Eradication of Blineage cells and regression of lymphoma in a patient treated with autologous T cells genetically engineered to recognize CD19. Blood 2010;116:4099-102.

56 Gust J, Hay KA, Hanafi L-A, et al. Endothelial activation and blood-brain barrier disruption in neurotoxicity after adoptive immunotherapy with CD19 CAR-T cells. Cancer Discov 2017:7:1404-19.

57 Hay KA, Hanafi L-A, Li D, et al. Kinetics and biomarkers of severe cytokine release syndrome after CD19 chimeric antigen receptormodified T-cell therapy. Blood 2017;130:2295-306.

58 Hill JA, Li D, Hay KA, et al. Infectious complications of CD19targeted chimeric antigen receptor-modified T-cell immunotherapy. Blood 2018;131:121-30. 
59 Lee DW, Gardner R, Porter DL, et al. Current concepts in the diagnosis and management of cytokine release syndrome. Blood 2014;124:188-95

60 Maude SG, Pulsipher SA, Rives MA. Analysis of safety data from 2 multicenter trials of ctl019 in pediatric and young adult patients with relapsed/refractory (R/R) B-Cell acute lymphoblastic leukemia (BALL) in 22nd Congress of the European-Hematology-Association. 22nd Congress of the European Hematology Association; 06/24/2017, Madrid, Spain, 2017:197-8.

61 Tomblyn M, Chiller T, Einsele H, et al. Guidelines for preventing infectious complications among hematopoietic cell transplantation recipients: a global perspective. Biol Blood Marrow Transplant 2009;15:1143-238.

62 Centers for Disease Control and Prevention, Infectious Diseases Society of America, American Society of Blood and Marrow Transplantation. Guidelines for preventing opportunistic infections among hematopoietic stem cell transplant recipients. Biol Blood Marrow Transplant 2000;6:7-83.

63 Sullivan KM, Dykewicz CA, Longworth DL, et al. Preventing opportunistic infections after hematopoietic stem cell transplantation: the centers for disease control and prevention, infectious diseases Society of America, and American Society for blood and marrow transplantation practice guidelines and beyond. Hematology Am Soc Hematol Educ Program 2001:392-421.

64 Trifilio S, Verma A, Mehta J. Antimicrobial prophylaxis in hematopoietic stem cell transplant recipients: heterogeneity of current clinical practice. Bone Marrow Transplant 2004;33:735-9.

65 Hill JA, Seo SK. How I prevent infections in patients receiving CD19-targeted chimeric antigen receptor T cells for B-cell malignancies. Blood 2020;136:925-35.

66 Cooksley CD, Avritscher EBC, Bekele BN, et al. Epidemiology and outcomes of serious influenza-related infections in the cancer population. Cancer 2005;104:618-28.

67 Engelhard D, Mohty B, de la Camara R, et al. European guidelines for prevention and management of influenza in hematopoietic stem cell transplantation and leukemia patients: summary of ECIL-4 (2011), on behalf of ECIL, a joint venture of EBMT, EORTC, ICHS, and ELN. Transpl Infect Dis 2013:15:219-32.

68 Kunisaki KM, Janoff EN. Influenza in immunosuppressed populations: a review of infection frequency, morbidity, mortality, and vaccine responses. Lancet Infect Dis 2009;9:493-504.

69 Sykes A, Gerhardt E, Tang L, et al. The effectiveness of trivalent inactivated influenza vaccine in children with acute leukemia. $J$ Pediatr 2017;191:218-24.

70 Bedognetti D, Zoppoli G, Massucco C, et al. Impaired response to influenza vaccine associated with persistent memory B cell depletion in non-Hodgkin's lymphoma patients treated with rituximab-containing regimens.. J.i. 2011:186:6044-55.

71 Abramson JS, Irwin KE, Frigault MJ, et al. Successful anti-CD19 CAR T-cell therapy in HIV-infected patients with refractory highgrade B-cell lymphoma. Cancer 2019;125:3692-8.

72 Bachanova V, Bishop MR, Dahi P, et al. Chimeric antigen receptor T cell therapy during the COVID-19 pandemic. Biol Blood Marrow Transplant 2020;26:1239-46.

73 Gardner RA, Finney O, Annesley C, et al. Intent-To-Treat leukemia remission by CD19 CAR T cells of defined formulation and dose in children and young adults. Blood 2017;129:3322-31.

74 Park JH, Rivière I, Gonen M, et al. Long-Term follow-up of CD19 CAR therapy in acute lymphoblastic leukemia. N Engl J Med 2018;378:449-59.

75 Lee DW, Santomasso BD, Locke FL, et al. ASTCT consensus grading for cytokine release syndrome and neurologic toxicity associated with immune effector cells. Biol Blood Marrow Transplant 2019;25:625-38.

76 Bedoya F, Frigault MJ, Maus MV. The Flipside of the power of engineered T cells: observed and potential toxicities of genetically modified T cells as therapy. Mol Ther 2017;25:314-20.

77 Common terminology criteria forAdverse events (CTCAE), 2010United States Department of Health and Human Services. Available: https://evs.nci.nih.gov/ftp1/CTCAE/CTCAE_4.03/CTCAE 4.03 2010-06-14_QuickReference 8.5x11.pdf

78 Acharya UH, Dhawale T, Yun S, et al. Management of cytokine release syndrome and neurotoxicity in chimeric antigen receptor (CAR) T cell therapy. Expert Rev Hematol 2019;12:195-205.

79 Davila ML, Riviere I, Wang X, et al. Efficacy and toxicity management of 19-28z CAR T cell therapy in B cell acute lymphoblastic leukemia. Sci Transl Med 2014;6:224ra25.

80 Porter D, Frey N, Wood PA, et al. Grading of cytokine release syndrome associated with the CAR T cell therapy tisagenlecleucel. J Hematol Oncol 2018;11:35.
81 Schuster SJ, Maziarz RT, Rusch ES, et al. Grading and management of cytokine release syndrome in patients treated with tisagenlecleucel in the JULIET trial. Blood Adv 2020;4:1432-9.

82 Sterner RM, Sakemura R, Cox MJ, et al. Gm-Csf inhibition reduces cytokine release syndrome and neuroinflammation but enhances CAR-T cell function in xenografts. Blood 2019;133:697-709.

83 Norelli M, Camisa B, Barbiera G, et al. Monocyte-Derived IL-1 and IL-6 are differentially required for cytokine-release syndrome and neurotoxicity due to CAR T cells. Nat Med 2018;24:739-48.

84 Brudno JN, Kochenderfer JN. Recent advances in car T-cell toxicity: mechanisms, manifestations and management. Blood Rev 2019;34:45-55.

85 Maude SL, Barrett D, Teachey DT, et al. Managing cytokine release syndrome associated with novel T cell-engaging therapies. Cancer J 2014;20:119-22.

86 Namuduri M, Brentjens RJ. Medical management of side effects related to CAR T cell therapy in hematologic malignancies. Expert Rev Hematol 2016;9:511-3.

87 Riegler LL, Jones GP, Lee DW. Current approaches in the grading and management of cytokine release syndrome after chimeric antigen receptor T-cell therapy. Ther Clin Risk Manag 2019;15:323-35.

88 Ali SA, Shi V, Maric I, et al. T cells expressing an anti-B-cell maturation antigen chimeric antigen receptor cause remissions of multiple myeloma. Blood 2016;128:1688-700.

89 Baer B, Dudley CV, Simons RM. Management principles associated with cytokine release syndrome. Semin Oncol Nurs 2019;35:p. 150931.

90 Shimabukuro-Vornhagen A, Gödel P, Subklewe M, et al. Cytokine release syndrome. J Immunother Cancer 2018;6:56.

91 Alvi RM, Frigault MJ, Fradley MG, et al. Cardiovascular events among adults treated with chimeric antigen receptor T-cells (CAR-T). J Am Coll Cardiol 2019;74:3099-108.

92 Howard SC, Jones DP, Pui C-H. The tumor lysis syndrome. N Engl J Med 2011;364:1844-54

93 Wang L-X, Chen X, Jia M, et al. Arthritis of large joints shown as a rare clinical feature of cytokine release syndrome after chimeric antigen receptor T cell therapy: a case report. Medicine 2018;97:e0455

94 Singer M, Deutschman CS, Seymour CW, et al. The third International consensus definitions for sepsis and septic shock (Sepsis-3). JAMA 2016;315:801-10.

95 Santomasso B, Bachier C, Westin J, et al. The other side of car T-cell therapy: cytokine release syndrome, neurologic toxicity, and financial burden. Am Soc Clin Oncol Educ Book 2019;39:433-44.

96 Turtle CJ, Hanafi L-A, Berger C, et al. CD19 CAR-T cells of defined CD4+:CD8+ composition in adult B cell ALL patients. J Clin Invest 2016;126:2123-38.

97 Lowe KL, Mackall CL, Norry E, et al. Fludarabine and neurotoxicity in engineered T-cell therapy. Gene Ther 2018;25:176-91.

98 Le RQ, Li L, Yuan W, et al. Fda approval summary: tocilizumab for treatment of chimeric antigen receptor T cell-induced severe or lifethreatening cytokine release syndrome. Oncologist 2018;23:943-7.

99 Gardner R, Leger KJ, Annesley CE, et al. Decreased rates of severe CRS seen with early intervention strategies for CD19 CAR-T cell toxicity management. Blood 2016;128:586

100 Kadauke S, Myers RM, Li Y, et al. Risk-Adapted preemptive tocilizumab to prevent severe cytokine release syndrome after CTL019 for pediatric B-cell acute lymphoblastic leukemia: a prospective clinical trial. J Clin Oncol 2020;in press

101 Ishii K, Shalabi H, Yates B, et al. Tocilizumab-Refractory Cytokine Release Syndrome (CRS) Triggered By Chimeric Antigen Receptor (CAR)-Transduced T Cells May Have Distinct Cytokine Profiles Compared to Typical CRS. Blood 2016;128:3358.

102 Strati P, furqan fateeha, Westin J, et al. Prognostic impact of dose, duration, and timing of corticosteroid therapy in patients with large B-cell lymphoma treated with standard of care axicabtagene ciloleucel (Axi-cel). JCO 2020;38:8011

103 Hashmi H, Bachmeier C, Chavez JC, et al. Haemophagocytic lymphohistiocytosis has variable time to onset following CD19 chimeric antigen receptor $\mathrm{T}$ cell therapy. $\mathrm{Br} \mathrm{J}$ Haematol 2019;187:e35-8.

104 La Rosée P. Treatment of hemophagocytic lymphohistiocytosis in adults. Hematology 2015;2015:190-6.

105 Sobiak J, Kazimierczak U, Kowalczyk DW, et al. Clinical and In Vitro Studies on Impact of High-Dose Etoposide Pharmacokinetics Prior Allogeneic Hematopoietic Stem Cell Transplantation for Childhood Acute Lymphoblastic Leukemia on the Risk of Post-Transplant Leukemia Relapse. Arch Immunol Ther Exp 2015:63:385-95. 
106 Johnson TS, Terrell CE, Millen SH, et al. Etoposide selectively ablates activated $\mathrm{T}$ cells to control the immunoregulatory disorder hemophagocytic lymphohistiocytosis. J Immunol 2014;192:84-91

107 Shah NN, Highfill SL, Shalabi H, et al. Cd4/Cd8 T-cell selection affects chimeric antigen receptor (CAR) T-cell potency and toxicity: updated results from a phase I anti-CD22 CAR T-cell trial. J Clin Oncol 2020;38:1938-50.

108 Ishii K, Pouzolles M, Chien CD, et al. Perforin-deficient CAR T cells recapitulate late-onset inflammatory toxicities observed in patients. J Clin Invest 2020;130:5425-43.

109 Ahmed N, Brawley VS, Hegde M, et al. Human epidermal growth factor receptor 2 (HER2) -specific chimeric antigen receptormodified T cells for the immunotherapy of HER2-positive sarcoma. J Clin Oncol 2015;33:1688-96.

110 Nastoupil LJ, Jain MD, Feng L, et al. Standard-Of-Care Axicabtagene Ciloleucel for relapsed or refractory large B-cell lymphoma: results from the US lymphoma CAR T Consortium. $J$ Clin Oncol 2020;38:3119-28.

111 Garfall AL, Lancaster E, Stadtmauer EA, et al. Posterior reversible encephalopathy syndrome (PRES) after infusion of Anti-Bcma CAR T cells (CART-BCMA) for multiple myeloma: successful treatment with cyclophosphamide. Blood 2016;128:5702

$112 \mathrm{Hu}$ Y, Sun J, Wu Z, et al. Predominant cerebral cytokine release syndrome in CD19-directed chimeric antigen receptor-modified T cell therapy. J Hematol Oncol 2016:9:70.

113 Lee DW, Kochenderfer JN, Stetler-Stevenson M, et al. T cells expressing CD19 chimeric antigen receptors for acute lymphoblastic leukaemia in children and young adults: a phase 1 dose-escalation trial. Lancet 2015;385:517-28.

114 Hunter BD, Jacobson CA. Car T-cell associated neurotoxicity: mechanisms, clinicopathologic correlates, and future directions. $J$ Natl Cancer Inst 2019;111:646-54.

115 JCAR015 in all: a Root-Cause investigation. Cancer Discov 2018;8:4-5

116 Fry TJ, Shah NN, Orentas RJ, et al. CD22-targeted CAR T cells induce remission in B-ALL that is naive or resistant to CD19targeted CAR immunotherapy. Nat Med 2018;24:20-8.

117 Schuster SJet al. Tisagenlecleucel in adult relapsed or refractory diffuse large B-cell lymphoma 2018;380:45-56.

118 Karschnia P, Jordan JT, Forst DA, et al. Clinical presentation, management, and biomarkers of neurotoxicity after adoptive immunotherapy with CAR T cells. Blood 2019;133:2212-21.

119 Torre M, Solomon IH, Sutherland CL, et al. Neuropathology of a case with fatal car T-cell-associated cerebral edema. J Neuropathol Exp Neurol 2018;77:877-82.

120 Britton JWet al. Electroencephalography (EEG): An Introductory Text and Atlas of Normal and Abnormal Findings in Adults, Children, and Infants. In: EK SL, Frey LC, eds. Chicago, 2016.

121 Schuster SJ, Svoboda J, Chong EA, et al. Chimeric antigen receptor T cells in refractory B-cell lymphomas. N Engl J Med 2017; $377: 2545-54$.

122 Cordeiro A, Bezerra ED, Hirayama AV, et al. Late events after treatment with CD19-Targeted chimeric antigen receptor modified T cells. Biol Blood Marrow Transplant 2020;26:26-33.

123 Chen F, Teachey DT, Pequignot E, et al. Measuring IL-6 and sIL-6R in serum from patients treated with tocilizumab and/or siltuximab following CAR T cell therapy. J Immunol Methods 2016;434:1-8

124 Frigault MJ, Dietrich J, Martinez-Lage M, et al. Tisagenlecleucel CAR T-cell therapy in secondary CNS lymphoma. Blood 2019;134:860-6.

125 Riedell PA, Bishop MR. Safety and efficacy of axicabtagene ciloleucel in refractory large B-cell lymphomas. Ther Adv Hematol 2020;11:204062072090289-99.

$126 \mathrm{Hu}$ Y, Sun J, Wu Z, et al. Predominant cerebral cytokine release syndrome in CD19-directed chimeric antigen receptor-modified T cell therapy. J Hematol Oncol 2016;9:70

127 Hirayama AV, Gauthier J, Hay KA, et al. The response to lymphodepletion impacts pfs in patients with aggressive nonHodgkin lymphoma treated with CD19 CAR T cells. Blood 2019;133:1876-87.

128 Arber DA, Orazi A, Hasserjian R, et al. The 2016 revision to the world Health organization classification of myeloid neoplasms and acute leukemia. Blood 2016;127:2391-405.

129 Ahmed N, Brawley V, Hegde M, et al. Her2-Specific chimeric antigen receptor-modified virus-specific T cells for progressive glioblastoma: a phase 1 dose-escalation trial. JAMA Oncol 2017;3:1094-101.

130 O'Rourke DM, Nasrallah MP, Desai A, et al. A single dose of peripherally infused EGFRvIll-directed CAR T cells mediates antigen loss and induces adaptive resistance in patients with recurrent glioblastoma. Sci Transl Med 2017;9:eaaa0984.
131 Logue JM, Zucchetti E, Bachmeier CA, et al. Immune reconstitution and associated infections following axicabtagene ciloleucel in relapsed or refractory large B-cell lymphoma. Haematologica 2020. doi:10.3324/haematol.2019.238634. [Epub ahead of print: $23 \mathrm{Apr}$ 2020].

132 Nahas GR, Komanduri KV, Pereira D, et al. Incidence and risk factors associated with a syndrome of persistent cytopenias after CAR-T cell therapy (PCTT). Leuk Lymphoma 2020;61:940-3.

133 Fried S, Avigdor A, Bielorai B, et al. Early and late hematologic toxicity following CD19 CAR-T cells. Bone Marrow Transplant 2019;54:1643-50.

134 Schaefer A, Saygin C, Maakaron J, et al. Cytopenias after chimeric antigen receptor T-cells (CAR-T) infusion; patterns and outcomes. Biol Blood Marrow Transplant 2019;25:S171.

135 Dong J, Chen H. Cardiotoxicity of anticancer therapeutics. Front Cardiovasc Med 2018;5:9

136 Common terminology criteria for adverse events (CTCAE) v5.0, 2017United States Department of Health and Human Services. Available: https://ctep.cancer.gov/protocolDevelopment/ electronic_applications/docs/CTCAE_v5_Quick_Reference_5x7. pdf

137 Burstein DS, Maude S, Grupp S, et al. Cardiac profile of chimeric antigen receptor $T$ cell therapy in children: a single-institution experience. Biol Blood Marrow Transplant 2018;24:1590-5.

138 Bovelli D, Plataniotis G, Roila F, et al. Cardiotoxicity of chemotherapeutic agents and radiotherapy-related heart disease: ESMO clinical practice guidelines. Ann Oncol 2010;21 Suppl 5:v277-82.

139 Plana JC, Galderisi M, Barac A, et al. Expert consensus for multimodality imaging evaluation of adult patients during and after cancer therapy: a report from the American Society of echocardiography and the European association of cardiovascular imaging. J Am Soc Echocardiogr 2014;27:911-39.

140 Awadalla M, Mahmood SS, Groarke JD, et al. Global longitudinal strain and cardiac events in patients with immune checkpoint Inhibitor-Related myocarditis. J Am Coll Cardiol 2020;75:467-78.

141 Mitra D, Basu S. Equilibrium radionuclide angiocardiography: its usefulness in current practice and potential future applications. World J Radiol 2012;4:421-30.

142 Steinherz LJ, Graham T, Hurwitz R, et al. Guidelines for cardiac monitoring of children during and after anthracycline therapy: report of the cardiology Committee of the Childrens cancer Study Group. Pediatrics 1992;89:942-9.

143 Januzzi JL, Camargo CA, Anwaruddin S, et al. The N-terminal ProBNP investigation of dyspnea in the emergency department (pride) study. Am J Cardiol 2005;95:948-54.

144 Roffi M, Patrono C, Collet J-P, et al. 2015 ESC guidelines for the management of acute coronary syndromes in patients presenting without persistent ST-segment elevation: Task force for the management of acute coronary syndromes in patients presenting without persistent ST-segment elevation of the European Society of cardiology (ESC). Eur Heart J 2016;37:267-315.

145 Thygesen K, Alpert JS, Jaffe AS, et al. Fourth universal definition of myocardial infarction (2018). J Am Coll Cardiol 2018;72:2231-64.

146 Korff S, Katus HA, Giannitsis E. Differential diagnosis of elevated troponins. Heart 2006;92:987-93.

147 Mahmood SS, Fradley MG, Cohen JV, et al. Myocarditis in patients treated with immune checkpoint inhibitors. J Am Coll Cardiol 2018;71:1755-64.

148 Redfearn DP, Ratib K, Marshall HJ, et al. Supraventricular tachycardia promotes release of troponin I in patients with norma coronary arteries. Int J Cardiol 2005;102:521-2.

149 McGowan JV, Chung R, Maulik A, et al. Anthracycline chemotherapy and cardiotoxicity. Cardiovasc Drugs Ther 2017;31:63-75.

150 Lipshultz SE, Lipsitz SR, Sallan SE, et al. Chronic progressive cardiac dysfunction years after doxorubicin therapy for childhood acute lymphoblastic leukemia. J Clin Oncol 2005;23:2629-36.

151 Cardinale D, Colombo A, Bacchiani G, et al. Early detection of anthracycline cardiotoxicity and improvement with heart failure therapy. Circulation 2015;131:1981-8.

152 Michel L, Rassaf T, Totzeck M. Biomarkers for the detection of apparent and subclinical cancer therapy-related cardiotoxicity. $J$ Thorac Dis 2018;10:S4282-95

153 Manrique CR, Park M, Tiwari N, et al. Diagnostic strategies for early recognition of cancer Therapeutics-Related cardiac dysfunction. Clin Med Insights Cardiol 2017;11:1179546817697983.

154 Specchia G, Buquicchio C, Pansini N, et al. Monitoring of cardiac function on the basis of serum troponin I levels in patients with acute leukemia treated with anthracyclines. J Lab Clin Med 2005;145:212-20. 
155 Fitzgerald JC, Weiss SL, Maude SL, et al. Cytokine release syndrome after chimeric antigen receptor T cell therapy for acute lymphoblastic leukemia. Crit Care Med 2017;45:e124-31.

156 Obstfeld AE, Frey NV, Mansfield K, et al. Cytokine release syndrome associated with chimeric-antigen receptor T-cell therapy: clinicopathological insights. Blood 2017;130:2569-72.

157 Pathan N, Hemingway CA, Alizadeh AA, et al. Role of interleukin 6 in myocardial dysfunction of meningococcal septic shock. Lancet 2004;363:203-9.

158 Borghi C, Rosei EA, Bardin T, et al. Serum uric acid and the risk of cardiovascular and renal disease. J Hypertens 2015;33:1729-41.

159 Muiesan ML, Agabiti-Rosei C, Paini A, et al. Uric acid and cardiovascular disease: an update. Eur Cardiol 2016;11:54-9.

160 Glantzounis GK, Tsimoyiannis EC, Kappas AM, et al. Uric acid and oxidative stress. Curr Pharm Des 2005;11:4145-51.

161 Zheng P-P, Kros JM, Li J. Approved CAR T cell therapies: ice bucket challenges on glaring safety risks and long-term impacts. Drug Discov Today 2018;23:1175-82.

162 Sørensen HT, Mellemkjaer L, Olsen JH, et al. Prognosis of cancers associated with venous thromboembolism. N Engl J Med 2000;343:1846-50

163 Khorana AA, Francis CW, Culakova E, et al. Thromboembolism is a leading cause of death in cancer patients receiving outpatient chemotherapy. J Thromb Haemost 2007;5:632-4.

164 Kuruvilla M, Gurk-Turner C. A review of warfarin dosing and monitoring. Proc 2001;14:305-6.

165 Horton JD, Bushwick BM. Warfarin therapy: evolving strategies in anticoagulation. Am Fam Physician 1999;59:635-46.

166 Mandalà M, Falanga A, Roila F, et al. Management of venous thromboembolism (VTe) in cancer patients: ESMO clinical practice guidelines. Ann Oncol 2011;22:vi85-92.

167 Farge D, Bounameaux H, Brenner B, et al. International clinical practice guidelines including guidance for direct oral anticoagulants in the treatment and prophylaxis of venous thromboembolism in patients with cancer. Lancet Oncol 2016;17:e452-66.

168 Streiff MB, Holmstrom B, Angelini D, et al. NCCN guidelines insights: cancer-associated venous thromboembolic disease, version 2.2018. J Nat/ Compr Canc Netw 2018;16:1289-303.

169 Ogba N, Arwood NM, Bartlett NL, et al. Chimeric antigen receptor T-cell therapy. J Natl Compr Canc Netw 2018;16:1092-106.

170 Linkins L-A, Choi PT, Douketis JD. Clinical impact of bleeding in patients taking oral anticoagulant therapy for venous thromboembolism: a meta-analysis. Ann Intern Med 2003;139:893-900.

171 White RH, Beyth RJ, Zhou H, et al. Major bleeding after hospitalization for deep-venous thrombosis. Am J Med 1999;107:414-24.

172 Gitter MJ, Jaeger TM, Petterson TM, et al. Bleeding and thromboembolism during anticoagulant therapy: a populationbased study in Rochester, Minnesota. Mayo Clin Proc 1995;70:725-33.

173 Paccani SR, Boncristiano M, Ulivieri C, et al. Nonsteroidal antiinflammatory drugs suppress T-cell activation by inhibiting p38 MAPK induction. J Biol Chem 2002;277:1509-13.

174 Iñiguez MA, Punzón C, Fresno M. Induction of cyclooxygenase-2 on activated T lymphocytes: regulation of $\mathrm{T}$ cell activation by cyclooxygenase-2 inhibitors. J Immunol 1999;163:111-9.

175 Wang K, Wei G, Liu D. Cd19: a biomarker for B cell development, lymphoma diagnosis and therapy. Exp Hematol Oncol 2012;1:36
176 Blanco E, Pérez-Andrés M, Arriba-Méndez S, et al. Age-Associated distribution of normal B-cell and plasma cell subsets in peripheral blood. J Allergy Clin Immunol 2018;141:2208-19.

177 Nutt SL, Hodgkin PD, Tarlinton DM, et al. The generation of antibody-secreting plasma cells. Nat Rev Immunol 2015;15:160-71.

178 Shinnakasu R, Kurosaki T. Regulation of memory B and plasma cell differentiation. Curr Opin Immunol 2017:45:126-31.

179 Compagno N, Malipiero G, Cinetto F, et al. Immunoglobulin replacement therapy in secondary hypogammaglobulinemia. Front Immunol 2014;5:626

180 Perez EE, Orange JS, Bonilla F, et al. Update on the use of immunoglobulin in human disease: A review of evidence. J Allergy Clin Immunol 2017;139:S1-46.

181 Doan A, Pulsipher MA. Hypogammaglobulinemia due to CAR T-cell therapy. Pediatr Blood Cancer 2018:65:e26914.

182 Arnold DE, Maude SL, Callahan CA, et al. Subcutaneous immunoglobulin replacement following CD19-specific chimeric antigen receptor T-cell therapy for B-cell acute lymphoblastic leukemia in pediatric patients. Pediatr Blood Cancer 2020;67:e28092.

183 Hill JA, Giralt S, Torgerson TR, et al. CAR-T - and a side order of IgG, to go? - Immunoglobulin replacement in patients receiving CAR-T cell therapy. Blood Rev 2019;38:100596.

184 FDA, U. Information About Immune Globulin (Human) Product Shortage U.S. FDA, 2019.

185 Maus MV, Haas AR, Beatty GL, et al. T cells expressing chimeric antigen receptors can cause anaphylaxis in humans. Cancer Immunol Res 2013;1:26-31.

186 Jhaveri KD, Rosner MH. Chimeric antigen receptor T cell therapy and the kidney. CJASN 2018;13:796-8.

187 Mato AR, Riccio BE, Qin L, et al. A predictive model for the detection of tumor lysis syndrome during $A M L$ induction therapy. Leuk Lymphoma 2006;47:877-83.

188 Montesinos P, Lorenzo I, Martín G, et al. Tumor lysis syndrome in patients with acute myeloid leukemia: identification of risk factors and development of a predictive model. Haematologica 2008;93:67-74.

189 Brentjens R, Yeh R, Bernal Y, et al. Treatment of chronic lymphocytic leukemia with genetically targeted autologous $T$ cells: case report of an unforeseen adverse event in a phase I clinical trial. Mol Ther 2010;18:666-8.

190 Luo H, Wang N, Huang L, et al. Inflammatory signatures for quick diagnosis of life-threatening infection during the CAR T-cell therapy. $J$ Immunother Cancer 2019;7:271.

191 Dietz AC, Grupp SA, Laetsch TW, et al. Patient-Reported quality of life (QOL) following CTL019 in pediatric and young adult patients (PTS) with relapsed/refractory ( $r / r)$ B-cell acute lymphoblastic leukemia (B-ALL). JCO 2017;35:10523

192 Ruark J, Mullane E, Cleary N, et al. Patient-Reported neuropsychiatric outcomes of long-term survivors after chimeric antigen receptor T cell therapy. Biol Blood Marrow Transplant 2020;26:34-43.

193 Tran G, Zafar SY. Financial toxicity and implications for cancer care in the era of molecular and immune therapies. Ann Trans/ Med 2018;6:166

194 Whittington MD, McQueen RB, Ollendorf DA, et al. Long-Term survival and value of chimeric antigen receptor T-cell therapy fo pediatric patients with relapsed or refractory leukemia. JAMA Pediatr 2018:172:1161-8.

195 Thornton Snider J, Brauer M, Kee R, et al. The potential impact of car T-cell treatment delays on Society. Am J Manag Care 2019;25:379-86. 